\title{
Improvement of bacterial blight and brown planthopper resistance in an elite restorer line Huazhan of Oryza
}

\author{
Youlun Xiao ${ }^{\mathrm{a}, \mathrm{b}, \mathrm{c}}$, Jinjiang $\mathrm{Li}^{\mathrm{b}}$, Jianghui Yu ${ }^{\mathrm{b}}$, Qiucheng Meng ${ }^{\mathrm{b}}$, Xiangyang Deng ${ }^{\mathrm{b}}, \mathrm{Zili}^{\mathrm{a}} \mathrm{i}^{\mathrm{a}}$, Guoying \\ $\mathrm{Xiao}^{\mathrm{b}, *}$ \\ ${ }^{a}$ College of Bioscience and Biotechnology, Hunan Agricultural University, Changsha 410128, China \\ ${ }^{\mathrm{b}}$ Key Laboratory of Agro-ecological Processes in Subtropical Region, Institute of Subtropical \\ Agriculture, Chinese Academy of Sciences, Changsha 410125, China \\ ${ }^{\mathrm{c}}$ Hunan Plant Protection Institute, Hunan Academy of Agricultural Sciences, Changsha 410125, China \\ * Corresponding author. Tel: +86-731-84619770; Fax: +86-731-84612685 \\ Email: xiaoguoying@isa.ac.cn
}

\begin{abstract}
Development of resistant varieties is one of the most economical and effective strategies to prevent rice from bacterial blight disease (BB) and brown planthopper (BPH), the two main pests jeopardizing rice production. The hybrid rice Tianyouhuazhan (TianfengA/Huazhan) has been widely used in rice production in China, but this hybrid is susceptible to BB and BPH. In this study, one BB resistance gene (Xa23) and two BPH resistance genes (Bphl4 and Bph15) were simultaneously introgressed into the restorer line Huazhan to improve the BB and BPH resistance of Tianyouhuazhan using marker-assisted backcrossing (MABC) strategy coupled with phenotypic selection. The results of identification of $\mathrm{BB}$ and $\mathrm{BPH}$ resistance revealed that almost all of the improved restorer lines and their derived hybrids showed high resistance (HR) or resistance (R) to BB and BPH. Almost all of the agronomic traits of improved restorer lines and their hybrids were similar to those of their respective original versions in field trial, except the 1000-grain weight of improved hybrids showed an extremely significant increase than that of Tianyouhuazhan. Plot yields test in 2013 and 2014 suggested that two improved hybrid combinations named as TianfengA/R43-06 and TianfengA/R43-07 had higher grain
\end{abstract}


yields per plot than Tianyouhuazhan and other improved hybrids. These results clearly indicate that pyramiding of Xa23, Bphl4 and Bphl5 genes is a useful approach for improving BB and BPH resistance, two hybrid combinations TianfengA/R43-06 and TianfengA/R43-07 could replace Tianyouhuazhan for extension in BB and/or BPH epidemic area in China.

Key words: Hybrid Rice; Restorer Line; Bacterial Blight Resistance; Brown Planthopper Resistance; Gene Pyramiding

\section{Introduction}

Rice is one of the most important staple food crops for more than half of the world's population. In China, hybrid rice has accounted for $57 \%$ of the total rice planting area and contributes $65 \%$ of the total rice yield (Yuan 2014). Bacterial blight disease (BB) caused by Xanthomonas oryzae pv. oryzae (Xoo) is one of the most serious rice diseases for both inbred and hybrid rice in Asia and can cause a reduction of rice yield by $20 \%$ to $30 \%$ and in some severe cases by up to $80 \%$ (Mew et al. 1993; Khan et al. 2014). Meanwhile, the brown planthopper (BPH) (Nilaparvata lugens Stål) is one of the most destructive insect pest of rice in Asia, which not only causes direct damage to rice plants by sucking the sap from the rice phloem, but also causes indirect damage by transmitting viral diseases such as grassy stunt virus and ragged stunt virus (Jena and Kim 2010; Cheng et al. 2013). The statistic data show that the annual direct losses of rice production in China caused by the BPH can be 1 to 1.5 billion $\mathrm{kg}$ (Cheng et al. 2013). Not surprisingly, development of resistant variety is the most economical, environmentally safe and effective strategy to control BB and BPH. However, the dominant rice varieties planted in China are less in resistance to both $\mathrm{BB}$ and $\mathrm{BPH}$, especially hybrid rice cultivars; 
more seriously, the rate of resistant variety is gradually declining year by year because breeders pay more attention to yield and quality traits (Zhang 2009; Deng et al. 2011). Thus, there is an urgent need to improve the resistance of hybrid rice to $\mathrm{BB}$ and $\mathrm{BPH}$.

Introgression of resistance genes into parents using marker-assisted backcrossing (MABC) strategy is a fast and highly efficient breeding method to improve diseases and insects resistance of hybrid rice. Until now, at least 39 genes related to BB resistance have been identified from cultivated and wild species of Oryza (Khan et al. 2014; Zhang et al. 2015). Nine of the 39 genes have been successfully cloned, i.e. Xa1, xa5, Xa10, xa13, Xa21, Xa23, xa25, Xa26 and Xa27 (Khan et al. 2014; Tian et al. 2014; Liu et al. 2015; Wang et al. 2015), but only a few genes have been widely used in the BB resistance breeding programs (Ding 2005; Zhang 2009; Rao et al. 2014). Xa4 gene was utilized in almost all of the commercial inbred and hybrid cultivars of indica rice in main rice-growing regions of China; now, the resistance to BB conferred by this gene has completely been lost in most rice planting area due to monoculture of Xa4 varieties (Zhang 2009). Xa21 gene has been widely used also in commercial rice cultivars in China (Cao et al. 2003; Khan et al. 2014), but this gene has no application values in Guangdong and Guangxi province of China where the dominant race IV and race $\mathrm{V}$ can infect Xa21 varieties (Zeng et al. 2002; Zhang 2009; He et al. 2011). Xa7 gene, which carries high resistance to most strains of $\mathrm{BB}$, was also utilized in a few BB-resistant cultivars from China and Phillipines (Vera Cruz et al. 2000; Ding 2005; Webb et al. 2010). Unfortunately, the strains virulent to $X a 7$ varieties had been isolated from the diseased leaves collected from paddy fields in China and Phillipines (Liu et al. 2004, 2007). Amongst all the known BB resistance genes, Xa23 gene identified from Oryza rufipogon is the most promising one for breeding BB-resistant cultivars because of its broad resistance spectrum and highly resistant level during all the growth stages (Zhang et al. 1998, 
2001). In recent years, Xa23 gene has been introduced into several restorer lines, and their hybrid combinations have been produced (Li et al. 2006a; Zhou et al. 2011). But there is no report till now that the hybrid rice cultivars with $X a 23$ gene have been utilized in large scale rice production.

Up to now, 28 genes for BPH resistance have been identified (Jena and Kim 2010; Fujita et al. 2013; Huang et al. 2013; Wu et al. 2014), in which 20 genes have been mapped onto different chromosomal locations and three genes including Bph2 (Bph26), Bph3 and Bph14, have been cloned (Du et al. 2009; Tamura et al. 2014; Liu et al. 2015). However, only a few genes have been widely used in breeding BPH resistance varieties (Jena and Kim 2010; Fujita et al. 2013). Since 1973, four BPH-resistant varieties IR26, IR36, IR56 and IR66, which harbor Bph1, bph2, Bph3 and bph4, respectively, were released in Asia and effectively alleviated the BPH damages (Cruz et al. 2011; Deng et al. 2011). Now, these varieties carrying Bphl or bph2 lose resistance to BPH in China (Huang et al. 2014). Recently, new BPH-resistant lines harboring one to three genes, including Bph6, Bph12, Bph14, Bph15 or Bph18, have been developed by marker-assisted selection (MAS), and the lines bearing two or three genes had stronger resistance to BPH than the lines bearing only one gene (Hu et al. 2012; Qiu et al. 2012; Hu et al. 2013). Bph14 and Bph15 identified from the wild rice Oryza officinalis conferred resistance to BPH biotype I, II and III (Huang et al. 2001). The Bph14 and Bph15 genes have been widely utilized in breeding BPH-resistant varieties in China now, and some varieties have been released in rice production, such as the male sterile lines Luohong4A and Bph68S carrying Bph14 and Bph15, the restorer line R476 and its hybrid rice Guangliangyou476 carrying Bph14 only (Xia et al. 2010; Li et al. 2011; Zhu et al. 2013a, b). These reports suggest a good future that Bph14 and Bph15 genes are very useful in developing BPH-resistant cultivars in China.

Gene pyramiding is one of the most effective solutions to diseases and insects resistance 
breakdown. The pyramided lines stacking multiple BPH or BB resistance genes showed broader spectrum, higher level and more durable resistance than the lines with only one gene (Singh et al. 2001; Sharma et al. 2004; Perez et al. 2008; Hu et al. 2012; Huang et al. 2012; Hu et al. 2013; Suh et al. 2013; Win et al. 2013). Moreover, new conventional varieties and hybrid combinations harboring several resistant traits could be developed by pyramiding multiple resistance genes for different traits. To date, $\mathrm{BB}$ and blast resistance genes have been pyramided into commercial varieties and hybrid rice parental lines through MABC (Zhan et al. 2012; Hari et al. 2013; Pan et al. 2013). But to our knowledge, there are few reports on simultaneous introgression of BB and BPH resistance in hybrid rice parental lines. Li et al (2006a, 2006b) obtained a pyramided restorer line named as R106 stacking Xa23, Bph14 and Bph15 in the genetic background of 9311 using multiple crosses and backcross, but from which there was no hybrid combination registered in China. Chen et al. (2013) pyramided Xa23 and Bph18 into Minghui86, Shuhui527 and Zhehui7954 by MABC, respectively, but there was no report about BB and $\mathrm{BPH}$ resistance of hybrid combinations from improved restorer lines till now.

Huazhan is an elite male parent for two-line hybrids (Lin et al. 2014b) and a restorer line for wild abortive cytoplasmic male sterile (WA-CMS) three-line hybrids (Yu et al. 2009; Xu 2013; Xu and Lin 2013; Lin et al. 2014a). Hybrid combinations derived from Huazhan, such as Tianyouhuazhan, Yueyouhuazhan, Rongyouhuazhan, Xinrongyouhuazhan, Wuyouhuazhan, Cliangyouhuazhan, Longliangyouhuazhan and Jingliangyouhuzhan, have been registered by National and/or Provincial Rice Variety Authorization Committee and widely planted in China due to their high yield potential, wide adaptability and good grain quality. In particular, Tianyouhuazhan (a hybrid of TianfengA and Huazhan) has been widely grown in the south and the middle-lower Yangtze River regions of China, and has been designated as check variety in national and some provincial regional trials, because of its 
wide adaptability and steady yields. However, Huazhan and Tianyouhuazhan are susceptible to BB and BPH, which lead to limited application area in rice production (Yu et al. 2009; Li et al. 2012). In this study, we successfully pyramided $\mathrm{Xa23}, \mathrm{Bph} 14$ and Bphl5 genes into Huazhan using MABC strategy coupled with phenotypic selection, and obtained new restorer lines and their hybrids with improvement in both $\mathrm{BB}$ and $\mathrm{BPH}$ resistance.

\section{Materials and Methods}

\subsection{Rice materials}

R106 (Li et al. 2006a, 2006b), derived from 9311///9311/CBB23//1826/B5, was used as resistant control for $\mathrm{BB}$ inoculation and the donor of $\mathrm{BB}$ resistance gene (Xa23) and $\mathrm{BPH}$ resistance genes (Bph14 and Bph15). Huazhan, which is widely utilized as a male parent in hybrid rice breeding, but susceptible to BB and BPH (Li et al. 2012), was used as the recipient of three resistance genes and the recurrent parent. TianfengA (Chen et al. 2006), a WA-CMS line, was used as the female parent to produce hybrid combinations. Tianyouhuazhan (Yu et al. 2009) was used as a control hybrid rice variety. B5 (Huang et al. 2001) and TN1 was used as a highly resistant and susceptible control for BPH infestation, respectively.

\subsection{Molecular markers and breeding scheme}

M-Xa23, located on chromosome 11, was a codominant sequence tagged site (STS) marker of 0.4 cM apart from the Xa23 locus (Gao et al. 2010). Bph14-2dom, a dominant and functional molecular marker used to detect Bph14 gene before 2014, was designed in this study by comparing the sequence of Bph14 with the sequence of Nipponbare in NCBI. The DNA oligo primers for amplifying 
Bph14-2dom were Bph14-2domF (5'-AGACCAGAAGCTATTCGGACTCC-3') and Bph14-2domR

(5'-TGTGAAGGGTGTGTGTGTGTCAC-3'). Bph14P/Bph14N, the codominant and functional molecular markers used to detect Bph14 gene in 2014, were designed according to the promoter and LRR regions of Bph14 gene (Zhou et al. 2013). MS5, located on chromosome 4, is a codominant SSR marker with the genetic distance of $0.3 \mathrm{cM}$ from Bph15 gene (Yang et al. 2004). The Xa23, Bph14 and Bph15 genes were simultaneously introgressed into an elite restorer line Huazhan following the MABC procedure (Fig.1) combined with phenotypic selection.

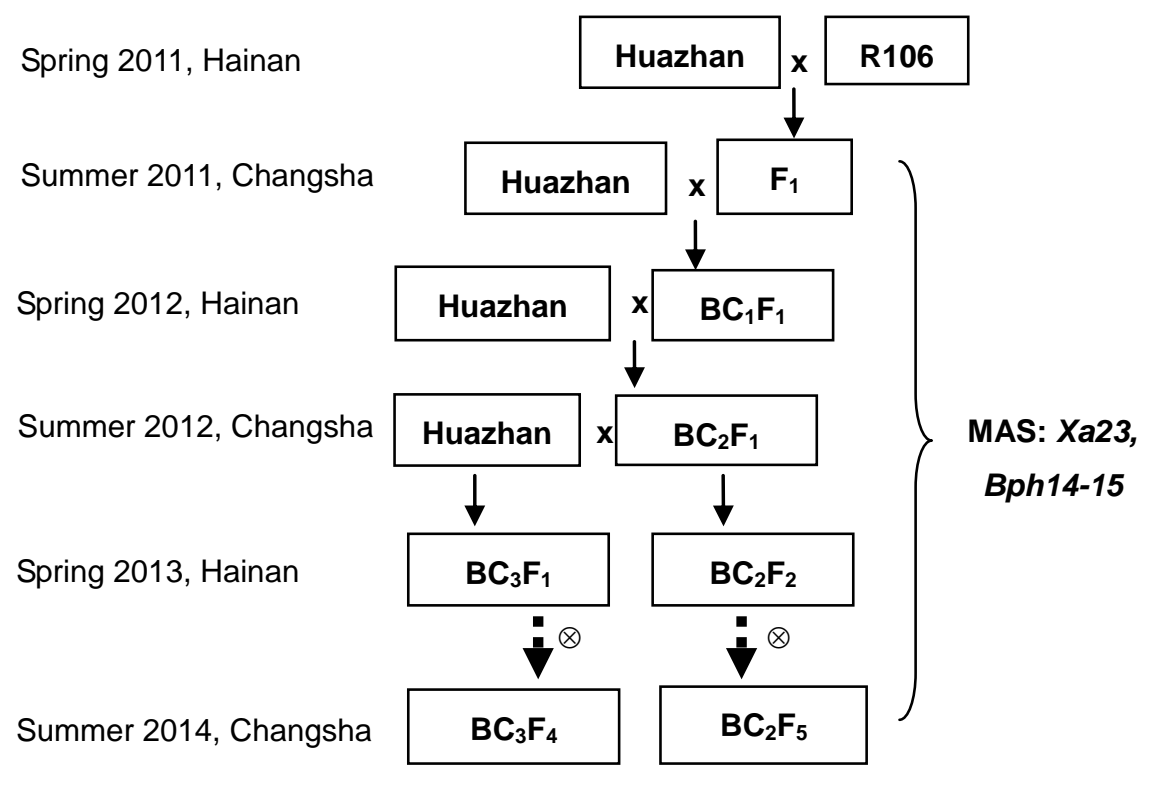

Fig. 1 MABC procedure for developing new restorer lines improved in BB and BPH resistance.

\subsection{Xoo strain and evaluation of $\mathrm{BB}$ resistance at booting stage}

2.3.1. Xoo strain: Zhe173 collected from China belonged to IV pathotype, provided by Hunan Rice Institute. PXO86 and PXO99 are representative pathotypes in Philippines, provided by Shanghai Jiao Tong University. The other nine strains collected from China, named as YN18, YN1, GD414, HeN11, ScYc-6, YN7, YN11, FuJ and YN24, are representatives of nine virulent pathotypes belonging 
to R1 to R9 (Liu et al. 2007), provided by Nanjing Agricultural University.

2.3.2. Incubation and inoculation of Xoo strain: twelve representative strains belonging to different pathotypes were incubated in NA liquid medium with shaking at $160 \mathrm{r} / \mathrm{min}$ and at $28{ }^{\circ} \mathrm{C}$ for 24 to 36 hours (Wu et al. 2007). The bacterial cell suspensions with concentrations of $3 \times 10^{8} \mathrm{cfu} / \mathrm{mL}$ were used to inoculate the rice plants by leaf-clipping method (Wu et al. 2007). The rice materials were sowed at Langli Experimental Station of our institute (Changsha, Hunan province, China) on June 15, 2014, and then 30 plants of each line were transplanted in field in space of $16.7 \mathrm{~cm} \times 20 \mathrm{~cm}$ on July 12 , 2014. Each material was inoculated for ten flag leaves at booting stage, and the LL (lesion lengths) was measured 21 days post-inoculation, then reaction of rice plant to BB was determined by the mean LL as described by Huang et al. (2012).

\subsection{Propagation of BPH nympha and evaluation of BPH resistance at seedling stage}

2.4.1. Propagation of BPH nympha: The BPH insects used for infestation were collected from early season rice fields at Changsha, Hunan province, China in June, 2014, and maintained on plants of rice variety $\mathrm{TN} 1$ at vigorous tillering stage.

2.4.2. Evaluation of BPH resistance: Modified bulk seedling test was used to evaluate $\mathrm{BPH}$ resistance of improved restorer lines and their hybrids (Li et al. 2006b). All rice materials were germinated in an incubator at $25^{\circ} \mathrm{C}$ on August 19, 2014 and the seedlings with similar and healthy growth of each material were transplanted after 7 days in $60 \mathrm{~cm}$ (length) $\times 40 \mathrm{~cm}$ (width) $\times 10 \mathrm{~cm}$ (height) plastic trays in greenhouse. Each material included three replications, and each replication contained 24 plants transplanted in two rows; the space of every replication was $8 \mathrm{~cm}$, the row space within a replication was $4 \mathrm{~cm}$. At three-leaf stage, the seedlings were infested with the 2 nd $\sim 3$ rd-instar 
nympha on density of eight to ten insects per seedling. When $95 \%$ of seedlings of TN1 were wither, the $\mathrm{BPH}$ resistance were evaluated according to Liu et al. (2002): resistance score $=0$ and resistance level $=$ immune $(\mathrm{IM})$ if dead seedling rate $\leq 1.0 \%$; resistance score $=1$ and resistance level $=$ high resistance (HR) if dead seedling rate between $1.1 \% \sim 10.0 \%$; resistance score $=3$ and resistance level $=$ resistance $(\mathrm{R})$ if dead seedling rate between $10.1 \% \sim 30.0 \%$; resistance score $=5$ and resistance level $=$ medium resistance $(\mathrm{MR})$ if dead seedling rate between $30.1 \% \sim 50.0 \%$; resistance score $=7$ and resistance level $=$ medium susceptible $(\mathrm{MS})$ if dead seedling rate between $50.1 \% \sim 70.0 \%$; resistance score $=9$ and resistance level $=$ susceptible $(\mathrm{S})$ if dead seedling rate $\geq 70.1 \%$.

\subsection{Evaluation of agronomic trait and plot yield}

To evaluate the agronomic traits under natural field condition, variety comparative test was continuously conducted in 2013 and 2014 at Langli Experimental Station of our institute (Changsha, Hunan province, China). The improved hybrids and Tianyouhuazhan (check hybrid) were sowed on June 15 , and then transplanted in fields on July 12 of every year. Each hybrid contained three plots, with each plot layout in randomized complete block design that contained 50 plants in five rows $(17 \mathrm{~cm}$ within-row space and $20 \mathrm{~cm}$ between-row space) in 2013; in addition, each plot consisted of 100 plants in ten rows in 2014. The improved restorer lines and Huazhan were sowed on May 29 and then transplanted on June 25, 2014, whereas the other field designs were the same as those in 2013. Normal water and fertilizer management, disease and pest control were conducted. The heading dates of the tested lines were recorded in fields, and the days from seeding to heading (DSH) was calculated based on the sowing and heading date. The plant height $(\mathrm{PH})$ of three normal plants in middle of the central row in each plot were measured at fully mature stage, and then these three plants were harvested to 
evaluate other agronomic traits in laboratory, including panicle length (PL), panicles per plant (PP), spikelet per panicle (SP), seed set (SS), 1000-grain weight (KW) and yield per plant (YP). The left plants of each plot were harvested and mixed with the grains of the three plants to assess grain yield per plot (GYP). The software DPS (V14.10) was used to determine significance of differences in agronomic traits and plot yields by least significant difference (LSD) method.

\section{Results}

\subsection{Introgression of $\mathrm{BB}$ and $\mathrm{BPH}$ resistance genes}

The entire breeding flowchart is shown in Fig.1. The BB- and BPH-resistant improvement of Huazhan was initiated in the spring of 2011 in Hainan, China, using Huazhan as a recurrent parent and R106 as the donor of Xa23, Bph14 and Bph15 genes. By use of MAS cooperated with phenotypic selection, three plants carrying three resistance genes were selected from 51 plants on the $\mathrm{BC}_{1} \mathrm{~F}_{1}$ generation, two individuals with three introgressive genes were picked from 35 individuals on the $\mathrm{BC}_{2} \mathrm{~F}_{1}$ generation, and three plants possessing the target genes were screened from 42 plants on the $\mathrm{BC}_{3} \mathrm{~F}_{1}$ generation, successively and respectively. In order to obtain lines homozygous in these three genes, 300 plants on the $\mathrm{BC}_{2} \mathrm{~F}_{2}$ generation were planted in Hainan, China in the spring of 2013, and 12 individuals harboring Xa23, Bph14 and Bph15 genes were selected out by M-Xa23, Bph14-2dom and MS5 markers respectively, among which Xa23 and Bph15 genes were homozygous (Fig.2a-c); 300 $\mathrm{BC}_{3} \mathrm{~F}_{2}$ plants from three $\mathrm{BC}_{3} \mathrm{~F}_{1}$ plants were grown in Changsha in the summer of 2013, and three individuals with Bph14 gene, homozygous Bph15 gene and homozygous Xa23 gene were picked up using the same DNA markers coupled with phenotypic selection. In the spring of 2014, twelve improved lines including R43-01 R43-12 were identified to be homozygous in BB and BPH 
resistance genes on the $\mathrm{BC}_{2} \mathrm{~F}_{4}$ generation (Fig.2e), and three improved lines (R43-13 R43-15) homozygous in three resistance genes were selected out on the $\mathrm{BC}_{3} \mathrm{~F}_{3}$ generation by use of $\mathrm{M}-\mathrm{Xa} 23$, Bph14P/ Bph14N and MS5 marker respectively (Fig.2d).

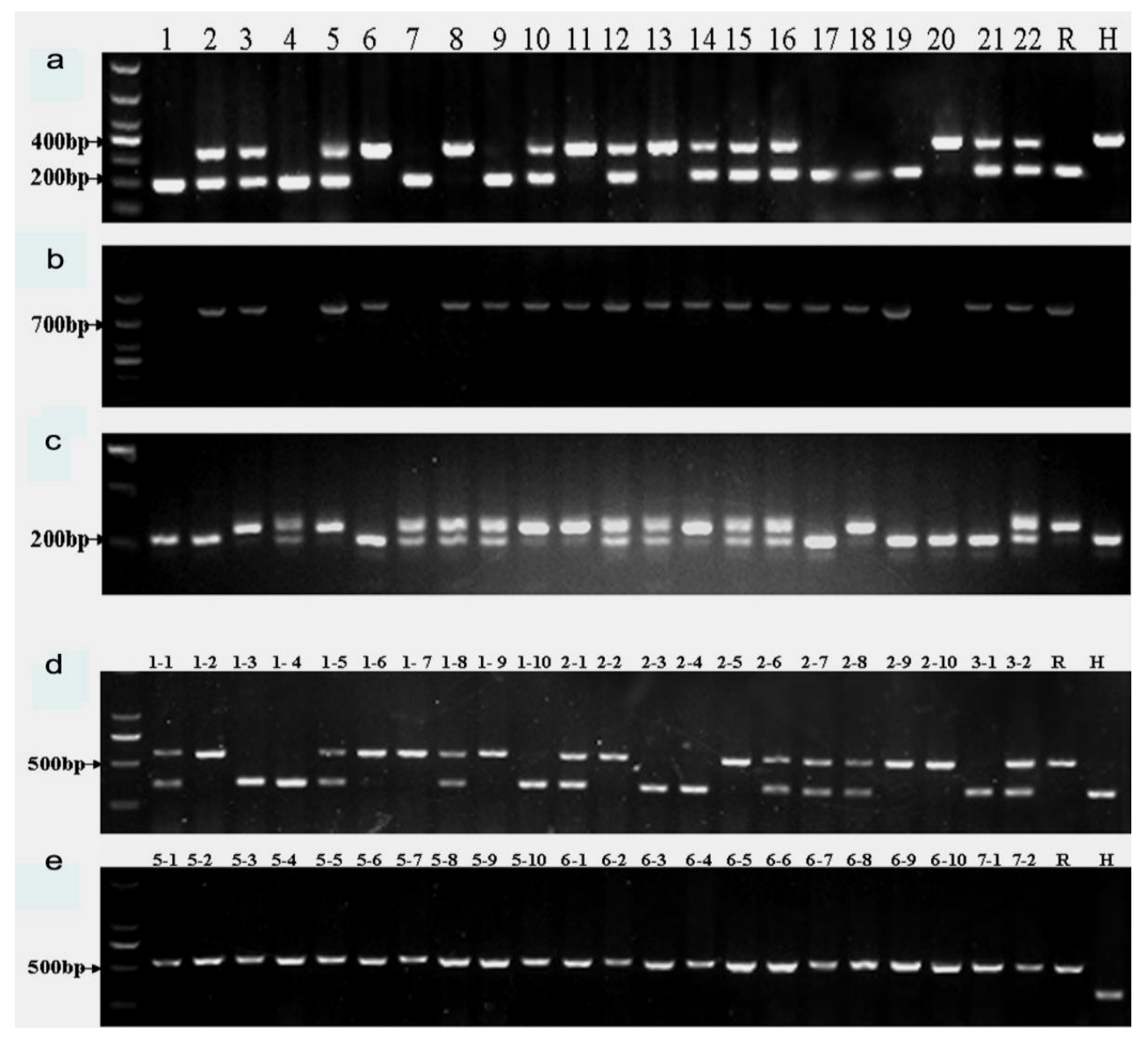

Fig. 2 Detection of $X a 23, B p h 14$ and $B p h 15$ genes on the generation of $\mathrm{BC}_{2} \mathrm{~F}_{2}(\mathrm{a}, \mathrm{b}, \mathrm{c}), \mathrm{BC}_{3} \mathrm{~F}_{3}(\mathrm{~d})$ and $\mathrm{BC}_{2} \mathrm{~F}_{4}$ (e). (a): a STS marker M-Xa23 was used for detecting Xa23; (b): a dominant and functional marker Bph14-2dom was used for detecting Bph14; (c): a SSR marker MS5 was used for detecting Bph15. Lane R and H are R106 and Huazhan, respectively. Lanes 1 to 22 represent 22 individual plants of improved restorer lines. For Xa23 gene, lanes 1, 4, 7, 9, 17, 18 and 19 are homozygous, and lane 2, 3, 5, 10, 12, 14, 15, 16, 21 and 22 are heterozygous; for Bph14 gene, all the lanes have except for lane 1, 4, 7 and 20; for Bph15 gene, lane 3, 5, 10,11, 14 and 18 are homozygous, and lane 4, 7, 8, 9, 12, 13, 15, 16 and 22 are heterozygous. (d) and (e): a codominant and functional marker Bph14N/ Bph14P were used for detecting Bph14. Lane R and H are R106 and Huazhan, respectively. Lane 1-1 to 3-2 and Lane 5-1 to 7-2 represent 44 individuals from 6 improved restorer lines; lane 1-2, 1-6, 1-7, 1-9, 2-2, 2-5, 2-9, 2-10 and 5-1 7-2 are homozygous, lane 1-1, 1-5, 1-8, 2-1, 2-6, 2-7, 2-8 and 3-2 are heterozygous.

\subsection{Evaluation of bacterial blight resistance}

The results of BB resistance on basis of the mean LL are shown in Table 1 and Table 2. TianfengA 
was found to be resistant to only three Xoo strains including YN7, YN11 and YN18, and be moderately or highly susceptible to the other nine Xoo strains with average LL ranging from 10.92 to $17.80 \mathrm{~cm}$; both Huazhan and Tianyouhuazhan showed medium resistant (MR), resistant (R) or highly resistant (HR) level of resistance to only four Xoo strains such as ScYc6, YN7, YN11 and YN18, and showed medium susceptible (MS), susceptible (S) or highly susceptible (HS) to the other eight Xoo strains, with mean LL ranging from 6.88 to $21.18 \mathrm{~cm}$ and 8.64 to $17.58 \mathrm{~cm}$, respectively. However, R106 and fifteen improved restorer lines with Xa23 gene showed very high level of resistance to all twelve Xoo strains with LL below $1.0 \mathrm{~cm}$, and the fifteen hybrids from improved restorer lines exhibited R or HR level of resistance to twelve Xoo strains with LL under $3.0 \mathrm{~cm}$. Amongst fifteen improved hybrid combinations, TianfengA/R43-04, TianfengA/R43-03 and TianfengA/R43-07 were with higher level of resistance to $\mathrm{BB}$ than other hybrids (Table 2; Fig.3). Overall, the improved restorer lines showed slightly higher level of resistance to BB than their corresponding hybrids. With the introgression of Xa23 gene, the resistance levels of improved restorer lines and their hybrids were promoted from at least MS to R or HR for the eight Xoo strains, and the resistance levels for the other four Xoo strains were sustained HR or promoted to HR. It indicates that the introgression of $\mathrm{Xa23}$ gene to restorer line is an effective method to promote BB resistance of hybrids. 
Table 1 BB resistance levels of the fifteen improved restorer lines, gene donor and recurrent parent ${ }^{\mathrm{a}}$

\begin{tabular}{|c|c|c|c|c|c|c|c|c|c|c|c|c|}
\hline \multirow{2}{*}{ Line $^{a}$} & \multicolumn{12}{|c|}{ Xoo strain } \\
\hline & Zhe173 & PXO86 & PXO99 & FuJ & GD414 & HeN11 & ScYc6 & YN1 & YN7 & YN11 & YN18 & YN24 \\
\hline R43-01 & $0.20^{\mathrm{b}}(\mathrm{HR})^{\mathrm{c}}$ & 0.20 (HR) & 0.13 (HR) & 0.12 (HR) & 0.15 (HR) & $0.25(\mathrm{HR})$ & 0.12 (HR) & 0.13 (HR) & $0.10(\mathrm{HR})$ & 0.13 (HR) & 0.10 (HR) & 0.33 (HR) \\
\hline $\mathrm{R} 43-02$ & $0.12(\mathrm{HR})$ & $0.25(\mathrm{HR})$ & $0.12(\mathrm{HR})$ & $0.13(\mathrm{HR})$ & $0.22(\mathrm{HR})$ & $0.18(\mathrm{HR})$ & $0.12(\mathrm{HR})$ & $0.12(\mathrm{HR})$ & $0.15(\mathrm{HR})$ & $0.13(\mathrm{HR})$ & $0.17(\mathrm{HR})$ & $0.17(\mathrm{HR})$ \\
\hline R43-03 & $0.13(\mathrm{HR})$ & $0.18(\mathrm{HR})$ & $0.15(\mathrm{HR})$ & $0.13(\mathrm{HR})$ & $0.18(\mathrm{HR})$ & $0.13(\mathrm{HR})$ & $0.10(\mathrm{HR})$ & $0.10(\mathrm{HR})$ & 0.13 (HR) & $0.15(\mathrm{HR})$ & $0.12(\mathrm{HR})$ & $0.27(\mathrm{HR})$ \\
\hline R43-04 & 0.27 (HR) & $0.17(\mathrm{HR})$ & $0.12(\mathrm{HR})$ & $0.12(\mathrm{HR})$ & $0.17(\mathrm{HR})$ & $0.20(\mathrm{HR})$ & 0.18 (HR) & $0.17(\mathrm{HR})$ & $0.10(\mathrm{HR})$ & 0.12 (HR) & 0.12 (HR) & $0.27(\mathrm{HR})$ \\
\hline R43-05 & 0.12 (HR) & 0.25 (HR) & $0.10(\mathrm{HR})$ & $0.10(\mathrm{HR})$ & $0.10(\mathrm{HR})$ & $0.17(\mathrm{HR})$ & $0.10(\mathrm{HR})$ & $0.13(\mathrm{HR})$ & $0.12(\mathrm{HR})$ & $0.15(\mathrm{HR})$ & $0.13(\mathrm{HR})$ & $0.27(\mathrm{HR})$ \\
\hline R43-06 & 0.18 (HR) & $0.15(\mathrm{HR})$ & $0.15(\mathrm{HR})$ & $0.20(\mathrm{HR})$ & $0.18(\mathrm{HR})$ & $0.22(\mathrm{HR})$ & $0.12(\mathrm{HR})$ & $0.13(\mathrm{HR})$ & $0.10(\mathrm{HR})$ & $0.10(\mathrm{HR})$ & $0.10(\mathrm{HR})$ & $0.28(\mathrm{HR})$ \\
\hline R43-07 & $0.13(\mathrm{HR})$ & $0.18(\mathrm{HR})$ & $0.15(\mathrm{HR})$ & $0.20(\mathrm{HR})$ & $0.12(\mathrm{HR})$ & $0.18(\mathrm{HR})$ & $0.13(\mathrm{HR})$ & $0.12(\mathrm{HR})$ & $0.13(\mathrm{HR})$ & $0.12(\mathrm{HR})$ & $0.13(\mathrm{HR})$ & $0.35(\mathrm{HR})$ \\
\hline R43-08 & $0.22(\mathrm{HR})$ & $0.40(\mathrm{HR})$ & $0.13(\mathrm{HR})$ & $0.18(\mathrm{HR})$ & $0.10(\mathrm{HR})$ & $0.63(\mathrm{HR})$ & $0.10(\mathrm{HR})$ & $0.15(\mathrm{HR})$ & $0.10(\mathrm{HR})$ & $0.13(\mathrm{HR})$ & $0.10(\mathrm{HR})$ & 0.33 (HR) \\
\hline R43-09 & $0.12(\mathrm{HR})$ & $0.15(\mathrm{HR})$ & $0.10(\mathrm{HR})$ & $0.13(\mathrm{HR})$ & $0.12(\mathrm{HR})$ & $0.17(\mathrm{HR})$ & $0.15(\mathrm{HR})$ & $0.12(\mathrm{HR})$ & $0.17(\mathrm{HR})$ & $0.13(\mathrm{HR})$ & $0.12(\mathrm{HR})$ & 0.32 (HR) \\
\hline R43-10 & $0.12(\mathrm{HR})$ & $0.23(\mathrm{HR})$ & $0.12(\mathrm{HR})$ & $0.10(\mathrm{HR})$ & $0.10(\mathrm{HR})$ & $0.15(\mathrm{HR})$ & $0.10(\mathrm{HR})$ & $0.10(\mathrm{HR})$ & $0.12(\mathrm{HR})$ & $0.13(\mathrm{HR})$ & 0.12 (HR) & $0.33(\mathrm{HR})$ \\
\hline R43-11 & 0.12 (HR) & 0.13 (HR) & $0.12(\mathrm{HR})$ & $0.15(\mathrm{HR})$ & $0.12(\mathrm{HR})$ & $0.13(\mathrm{HR})$ & 0.18 (HR) & $0.17(\mathrm{HR})$ & $0.13(\mathrm{HR})$ & $0.13(\mathrm{HR})$ & $0.12(\mathrm{HR})$ & 0.25 (HR) \\
\hline R43-12 & $0.35(\mathrm{HR})$ & $0.28(\mathrm{HR})$ & $0.15(\mathrm{HR})$ & $0.12(\mathrm{HR})$ & $0.12(\mathrm{HR})$ & $0.18(\mathrm{HR})$ & $0.15(\mathrm{HR})$ & $0.13(\mathrm{HR})$ & 0.18 (HR) & 0.13 (HR) & 0.12 (HR) & $0.30(\mathrm{HR})$ \\
\hline R43-13 & $0.15(\mathrm{HR})$ & $0.22(\mathrm{HR})$ & $0.15(\mathrm{HR})$ & $0.20(\mathrm{HR})$ & $0.13(\mathrm{HR})$ & $0.23(\mathrm{HR})$ & $0.10(\mathrm{HR})$ & $0.13(\mathrm{HR})$ & $0.12(\mathrm{HR})$ & $0.12(\mathrm{HR})$ & $0.12(\mathrm{HR})$ & 0.27 (HR) \\
\hline R43-14 & 0.17 (HR) & 0.18 (HR) & $0.12(\mathrm{HR})$ & $0.15(\mathrm{HR})$ & $0.10(\mathrm{HR})$ & $0.15(\mathrm{HR})$ & $0.15(\mathrm{HR})$ & $0.13(\mathrm{HR})$ & $0.10(\mathrm{HR})$ & $0.15(\mathrm{HR})$ & $0.15(\mathrm{HR})$ & $0.33(\mathrm{HR})$ \\
\hline R43-15 & $0.13(\mathrm{HR})$ & 0.18 (HR) & $0.10(\mathrm{HR})$ & $0.13(\mathrm{HR})$ & $0.13(\mathrm{HR})$ & $0.12(\mathrm{HR})$ & $0.17(\mathrm{HR})$ & $0.15(\mathrm{HR})$ & $0.13(\mathrm{HR})$ & $0.15(\mathrm{HR})$ & $0.12(\mathrm{HR})$ & $0.15(\mathrm{HR})$ \\
\hline R106 & 0.68 (HR) & $0.50(\mathrm{HR})$ & $0.36(\mathrm{HR})$ & 0.38 (HR) & $0.32(\mathrm{HR})$ & $0.30(\mathrm{HR})$ & $0.26(\mathrm{HR})$ & $0.34(\mathrm{HR})$ & $0.40(\mathrm{HR})$ & $0.26(\mathrm{HR})$ & $0.34(\mathrm{HR})$ & $0.32(\mathrm{HR})$ \\
\hline Huazhan & $6.88(\mathrm{MS})$ & $11.60(\mathrm{MS})$ & 9.68 (MS) & $21.18(\mathrm{HS})$ & 7.22 (MS) & $10.82(\mathrm{MS})$ & 4.17 (MR) & $7.02(\mathrm{MS})$ & 4.20 (MR) & $1.55(\mathrm{R})$ & $1.45(\mathrm{R})$ & $12.92(\mathrm{~S})$ \\
\hline
\end{tabular}

${ }^{\mathrm{a}}$ For the improved lines, R43-01 R43-12 were on generation of $\mathrm{BC}_{2} \mathrm{~F}_{5}, \mathrm{R} 43-13 \sim \mathrm{R} 43-15$ were on generation of $\mathrm{BC}_{3} \mathrm{~F}_{4} \cdot{ }^{\mathrm{b}}$ The lesion length (cm) was averaged over five replications. ${ }^{\mathrm{c}}{ }$ The

resistance levels to BB were scaled according to Huang et al (2012). 
Table 2 BB resistance levels of the fifteen improved hybrid combinations, hybrid check Tianyouhuazhan and its parents ${ }^{\mathrm{a}}$

\begin{tabular}{|c|c|c|c|c|c|c|c|c|c|c|c|c|}
\hline \multirow{2}{*}{ Line or hybrid $^{\mathrm{a}}$} & \multicolumn{12}{|c|}{ Xoo strain } \\
\hline & Zhe173 & PXO86 & PXO99 & FuJ & GD414 & HeN11 & ScYc6 & YN1 & YN7 & YN11 & YN18 & YN24 \\
\hline TianfengA/R43-01 & $0.88^{\mathrm{b}}(\mathrm{HR})^{\mathrm{c}}$ & $1.62(\mathrm{R})$ & $0.60(\mathrm{HR})$ & $0.40(\mathrm{HR})$ & $0.60(\mathrm{HR})$ & $0.66(\mathrm{HR})$ & 0.46 (HR) & $0.56(\mathrm{HR})$ & $0.26(\mathrm{HR})$ & $0.30(\mathrm{HR})$ & $0.30(\mathrm{HR})$ & $0.66(\mathrm{HR})$ \\
\hline TianfengA/R43-02 & $0.68(\mathrm{HR})$ & $1.02(\mathrm{R})$ & $0.48(\mathrm{HR})$ & $0.36(\mathrm{HR})$ & $0.32(\mathrm{HR})$ & $0.44(\mathrm{HR})$ & $0.74(\mathrm{HR})$ & $0.36(\mathrm{HR})$ & 0.20 (HR) & $0.26(\mathrm{HR})$ & $0.30(\mathrm{HR})$ & $0.42(\mathrm{HR})$ \\
\hline TianfengA/R43-03 & $0.84(\mathrm{HR})$ & $1.34(\mathrm{R})$ & $0.52(\mathrm{HR})$ & $0.30(\mathrm{HR})$ & $0.42(\mathrm{HR})$ & $0.46(\mathrm{HR})$ & $0.32(\mathrm{HR})$ & $0.46(\mathrm{HR})$ & $0.28(\mathrm{HR})$ & $0.28(\mathrm{HR})$ & $0.22(\mathrm{HR})$ & $0.54(\mathrm{HR})$ \\
\hline TianfengA/R43-04 & 0.96 (HR) & $0.78(\mathrm{HR})$ & $0.66(\mathrm{HR})$ & $0.32(\mathrm{HR})$ & $0.48(\mathrm{HR})$ & $0.64(\mathrm{HR})$ & $0.34(\mathrm{HR})$ & $0.74(\mathrm{HR})$ & $0.20(\mathrm{HR})$ & $0.18(\mathrm{HR})$ & $0.14(\mathrm{HR})$ & $0.52(\mathrm{HR})$ \\
\hline TianfengA/R43-05 & $0.76(\mathrm{HR})$ & $1.60(\mathrm{R})$ & $0.40(\mathrm{HR})$ & $0.32(\mathrm{HR})$ & $0.34(\mathrm{HR})$ & $0.60(\mathrm{HR})$ & $0.50(\mathrm{HR})$ & $0.42(\mathrm{HR})$ & $0.24(\mathrm{HR})$ & 0.24 (HR) & $0.36(\mathrm{HR})$ & 0.40 (HR) \\
\hline TianfengA/R43-06 & $0.72(\mathrm{HR})$ & $1.64(\mathrm{R})$ & $0.64(\mathrm{HR})$ & $0.38(\mathrm{HR})$ & $0.48(\mathrm{HR})$ & $0.56(\mathrm{HR})$ & $0.68(\mathrm{HR})$ & 0.44 (HR) & 0.40 (HR) & $0.34(\mathrm{HR})$ & $0.24(\mathrm{HR})$ & $0.50(\mathrm{HR})$ \\
\hline TianfengA/R43-07 & $0.74(\mathrm{HR})$ & $1.36(\mathrm{R})$ & $0.30(\mathrm{HR})$ & $0.24(\mathrm{HR})$ & $0.26(\mathrm{HR})$ & $0.66(\mathrm{HR})$ & $0.38(\mathrm{HR})$ & $0.62(\mathrm{HR})$ & $0.16(\mathrm{HR})$ & $0.38(\mathrm{HR})$ & $0.20(\mathrm{HR})$ & $0.40(\mathrm{HR})$ \\
\hline TianfengA/R43-08 & $1.10(\mathrm{R})$ & $2.35(\mathrm{R})$ & $0.55(\mathrm{HR})$ & $0.43(\mathrm{HR})$ & $0.45(\mathrm{HR})$ & $0.38(\mathrm{HR})$ & $0.45(\mathrm{HR})$ & $0.63(\mathrm{HR})$ & 0.48 (HR) & $0.38(\mathrm{HR})$ & $0.30(\mathrm{HR})$ & 0.75 (HR) \\
\hline TianfengA/R43-09 & $0.86(\mathrm{HR})$ & $2.26(\mathrm{R})$ & $0.48(\mathrm{HR})$ & $0.64(\mathrm{HR})$ & $0.50(\mathrm{HR})$ & $0.56(\mathrm{HR})$ & 0.46 (HR) & $0.82(\mathrm{HR})$ & 0.24 (HR) & $0.40(\mathrm{HR})$ & $0.50(\mathrm{HR})$ & $0.46(\mathrm{HR})$ \\
\hline TianfengA/R43-10 & $0.64(\mathrm{HR})$ & $2.44(\mathrm{R})$ & $0.42(\mathrm{HR})$ & $0.44(\mathrm{HR})$ & $0.38(\mathrm{HR})$ & $0.44(\mathrm{HR})$ & $0.56(\mathrm{HR})$ & $0.48(\mathrm{HR})$ & $0.24(\mathrm{HR})$ & $0.26(\mathrm{HR})$ & $0.16(\mathrm{HR})$ & $0.44(\mathrm{HR})$ \\
\hline TianfengA/R43-11 & $0.44(\mathrm{HR})$ & $2.52(\mathrm{R})$ & $0.52(\mathrm{HR})$ & $0.92(\mathrm{HR})$ & $0.34(\mathrm{HR})$ & $0.66(\mathrm{HR})$ & $0.60(\mathrm{HR})$ & $0.66(\mathrm{HR})$ & $0.38(\mathrm{HR})$ & $0.40(\mathrm{HR})$ & $0.22(\mathrm{HR})$ & $0.58(\mathrm{HR})$ \\
\hline TianfengA/R43-12 & $1.54(\mathrm{R})$ & $2.16(\mathrm{R})$ & $1.34(\mathrm{R})$ & $0.46(\mathrm{HR})$ & $0.30(\mathrm{HR})$ & $0.86(\mathrm{HR})$ & $0.54(\mathrm{HR})$ & $0.58(\mathrm{HR})$ & $0.24(\mathrm{HR})$ & $0.36(\mathrm{HR})$ & $0.36(\mathrm{HR})$ & $0.86(\mathrm{HR})$ \\
\hline TianfengA/R43-13 & $1.28(\mathrm{R})$ & $2.24(\mathrm{R})$ & $1.32(\mathrm{R})$ & $0.50(\mathrm{HR})$ & $0.60(\mathrm{HR})$ & $1.22(\mathrm{R})$ & $0.68(\mathrm{HR})$ & $1.84(\mathrm{R})$ & $0.34(\mathrm{HR})$ & 0.46 (HR) & $0.28(\mathrm{HR})$ & $0.64(\mathrm{HR})$ \\
\hline TianfengA/R43-14 & $1.20(\mathrm{R})$ & $1.52(\mathrm{R})$ & $0.44(\mathrm{HR})$ & $0.42(\mathrm{HR})$ & $0.54(\mathrm{HR})$ & $0.70(\mathrm{HR})$ & $0.38(\mathrm{HR})$ & $0.78(\mathrm{HR})$ & $0.26(\mathrm{HR})$ & $0.32(\mathrm{HR})$ & $0.32(\mathrm{HR})$ & $0.64(\mathrm{HR})$ \\
\hline TianfengA/R43-15 & $1.42(\mathrm{R})$ & $2.72(\mathrm{R})$ & $0.50(\mathrm{HR})$ & $0.28(\mathrm{HR})$ & $0.36(\mathrm{HR})$ & $0.54(\mathrm{HR})$ & $0.36(\mathrm{HR})$ & $1.62(\mathrm{R})$ & $0.42(\mathrm{HR})$ & $0.14(\mathrm{HR})$ & $0.14(\mathrm{HR})$ & $0.64(\mathrm{HR})$ \\
\hline Tianyouhuazhan & 11.06 (MS) & $14.34(\mathrm{~S})$ & $9.52(\mathrm{MS})$ & $17.58(\mathrm{~S})$ & $11.26(\mathrm{~S})$ & $8.80(\mathrm{MS})$ & 3.50 (MR) & 8.64 (MS) & 0.42 (HR) & $0.56(\mathrm{HR})$ & $0.66(\mathrm{HR})$ & $17.20(\mathrm{~S})$ \\
\hline TianfengA & $15.00(\mathrm{~S})$ & $16.02(\mathrm{~S})$ & $11.02(\mathrm{MS})$ & $16.82(\mathrm{~S})$ & $10.92(\mathrm{MS})$ & $17.12(\mathrm{~S})$ & $17.80(\mathrm{~S})$ & $16.84(\mathrm{~S})$ & $0.48(\mathrm{HR})$ & $0.52(\mathrm{HR})$ & $0.54(\mathrm{HR})$ & $15.60(\mathrm{~S})$ \\
\hline Huazhan & $6.88(\mathrm{MS})$ & $11.60(\mathrm{MS})$ & 9.68 (MS) & 21.18 (HS) & $7.22(\mathrm{MS})$ & $10.82(\mathrm{MS})$ & 4.17 (MR) & $7.02(\mathrm{MS})$ & 4.20 (MR) & $1.55(\mathrm{R})$ & $1.45(\mathrm{R})$ & $12.92(\mathrm{~S})$ \\
\hline
\end{tabular}

${ }^{\mathrm{a}}$ The hybrids TianfengA/R43-01 TianfengA/R43-15 were generated using R43-01 to R43-15 as male parent crossed with TianfengA, respectively. ${ }^{\mathrm{b}}$ The lesion length (cm) was averaged over five replications. ${ }^{\mathrm{c}}$ The resistance levels to BB were scaled according to Huang et al (2012) 


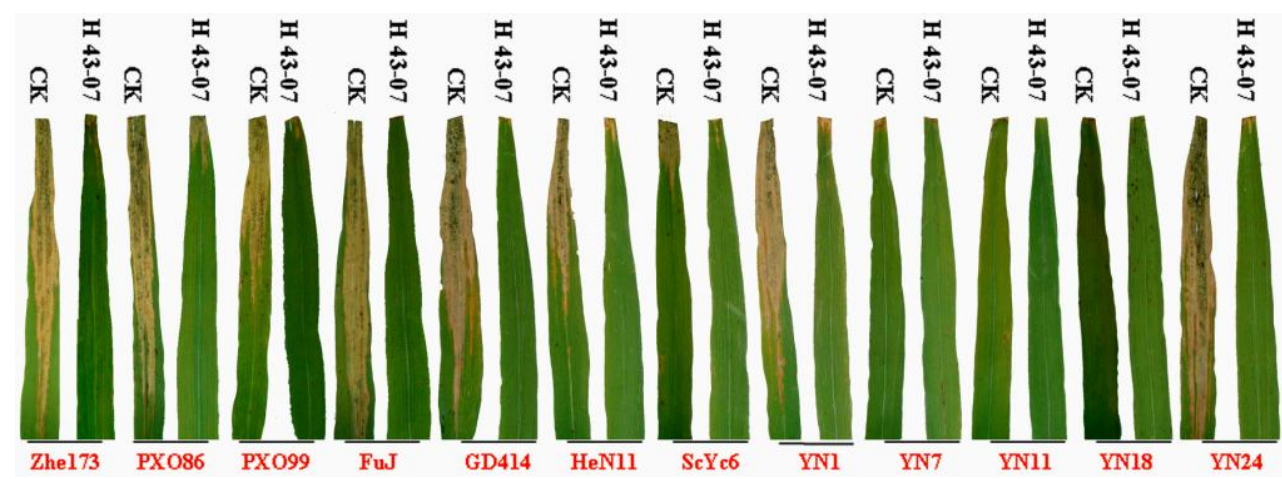

Fig.3 Comparison of BB resistance to 12 Xoo strain between the improved hybrid rice TianfengA/R43-7 and the control Tianyouhuazhan. CK represents control hybrid Tianyouhuazhan, H43-07 represents the improved hybrid combination TianfengA/R43-07.

\subsection{Evaluation of brown planthopper resistance}

The results of BPH resistance based on average resistance scores are displayed in Fig.4. The average BPH resistance scores of fifteen improved restorer lines homozygous in Bphl4 and Bphl5 loci were less than 3.0, whereas the average resistance score of Huazhan was 6.3 (Fig.4a). It suggested that the BPH resistance of improved restorer lines was significantly stronger than that of Huazhan. Amongst fifteen improved restorer lines, five lines including R43-01, R43-02, R43-05, R43-11 and R43-12 were highly resistant to BPH with the average scores less than 1.0 (Fig.4a), which were similar to the highly resistant control variety B5. All the improved hybrids except TianfengA/R43-09 (resistance score $=3.7$ ) were also less than 3.0, while the average resistance scores of TianfengA and Tianyouhuazhan were 5.7 and 5.0, respectively (Fig.4b). This indicated that the fifteen improved hybrids had much higher resistance level than Tianyouhuazhan. In the fifteen improved hybrid combinations, four hybrids including TianfengA/R43-01, TianfengA/R43-02, TianfengA/R43-04 and TianfengA/R43-12 were highly resistant to BPH with the average scores less than 1.0 (Fig.4b; Fig.5). Furthermore, BPH bioassay also showed that the improved restorer lines had slightly higher or similar resistance to BPH than their corresponding hybrids (Fig.4b). The higher the resistance level of a restorer line was, the 
higher the resistance level of its corresponding hybrid was. For example, the mean resistance scores of restorer lines R43-03 and R43-08 were 1.33 and 1.67 respectively, and the resistance scores of the corresponding hybrids TianfengA/R43-03 and TianfengA/R43-08 were 1.67 and 2.33 respectively. These findings indicated that pyramiding of Bphl4 and Bphl5 genes in genetic background of Huazhan could significantly improve BPH resistance of this restorer line and its hybrid, and the resistance of restorer line was positively correlative to that of its hybrid.
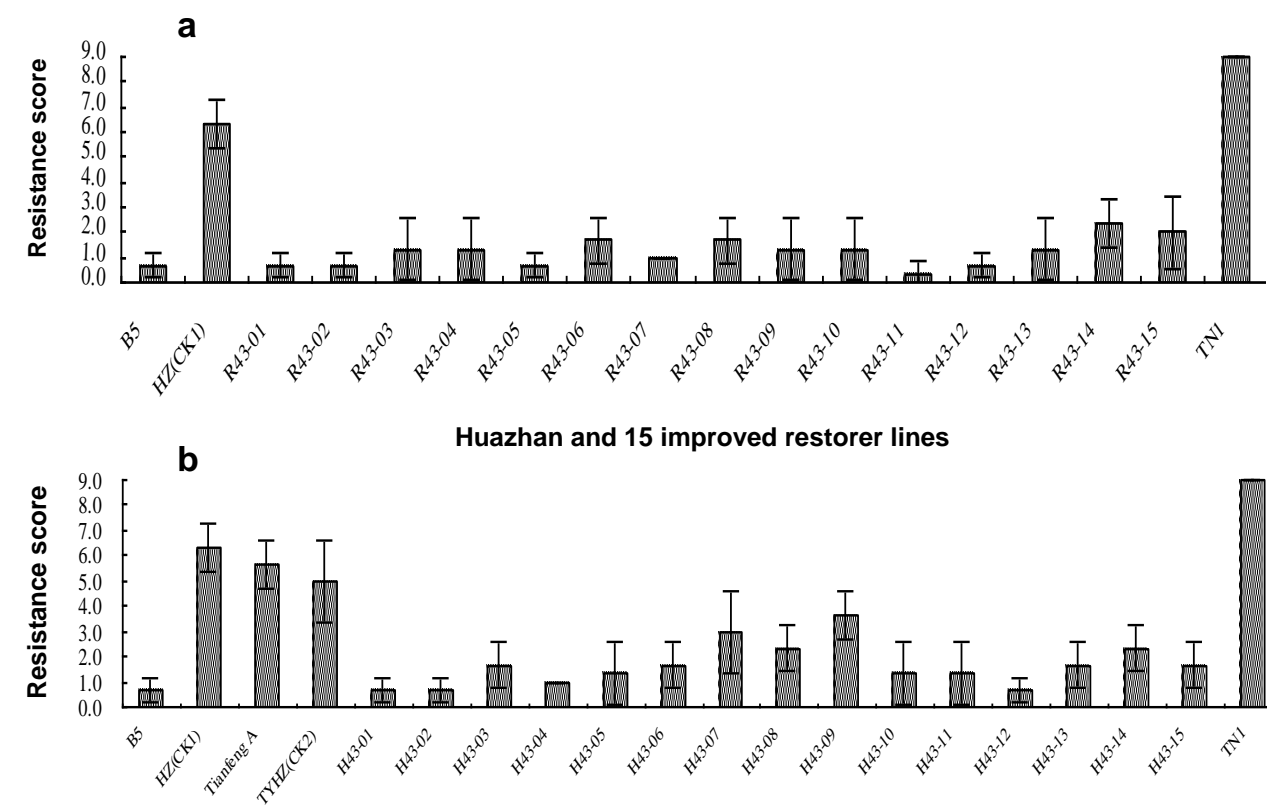

Tianyouhuazhan and 15 improved hybrid combinations

Fig.4 The BPH resistance scores of the improved restorer lines, improved hybrids, control hybrid and their parents. (a) The resistance scores of fifteen improved restorer lines and recurrent parent Huazhan in the modified bulk seedling test in greenhouse. (b) The resistance scores of the improved hybrids from improved restorer lines, control hybrid and their parents in the modified bulk seedling test. HZ represents the recurrent parent Huazhan, TYHZ represents the hybrid Tianyouhuazhan. R43-01 R43-15 represent the fifteen improved restorer lines, and H43-01 H43-15 represent the fifteen improved hybrid combinations derived from TianfengA crossing with R43-01 R43-15, respectively.

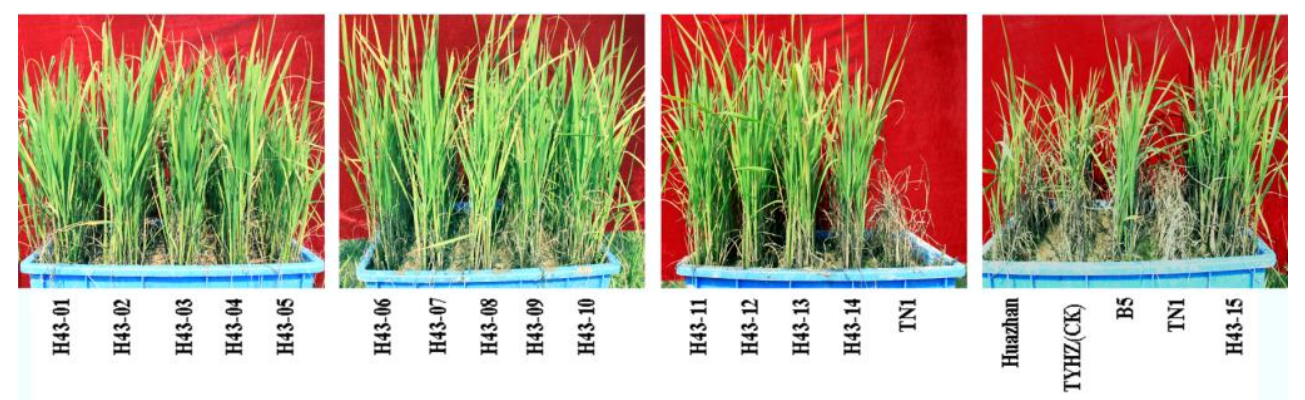


Fig.5 Performance of BPH resistance level of 15 improved hybrids, control hybrid Tianyouhuazhan and their parents at seedling stage. TN1 was used as BPH susceptible control, B5 as BPH resistant control, TYHZ (Tianyouhuazhan) as check hybrid. H43-01 H43-15 reprensent 15 improved hybrids derived from 15 improved restorer lines, respectively.

\subsection{Evaluation of agronomic traits}

Eight agronomic traits of Huazhan, Tianyouhuazhan, fifteen improved restorer lines and their hybrids were evaluated. The results showed that most of the improved restorer lines were superior to the recurrent parent Huazhan in some agronomic traits like PL, SP, KW, etc. (Table 3). For example, almost all of the improved restorer lines displayed significant increase $(\mathrm{P}<0.01)$ in $\mathrm{KW}$ compared with the recurrent parent Huazhan (Table 3). Accordingly, the KW of all improved hybrid combinations were significantly heavier $(\mathrm{P}<0.01)$ than that of Tianyouhuazhan (Table 4$)$, which displayed higher yield potential. However, most of the other agronomic traits of improved hybrid combinations were quite similar to those of the control Tianyouhuazhan. There was no significant difference $(\mathrm{P}>0.05)$ in PP, PL, SS and YP between all improved hybrid combinations and Tianyouhuazhan (Table 4). Compared with the control hybrid Tianyouhuazhan, one hybrid TianfengA/R43-11 displayed longer DSH $(\mathrm{P}<0.01)$, two hybrids TianfengA/R43-11 $(\mathrm{P}<0.01)$ and TianfengA/R43-12 $(\mathrm{P}<0.05)$ showed higher PH, one hybrid TianfengA/R43-04 was of less SP $(\mathrm{P}<0.05)$ (Table 4). Overall, there was no obviously negative effect on agronomic traits while simultaneously pyramiding BB and BPH resistance genes into Huazhan. 
Table 3 Comparison of agronomic traits between fifteen improved restorer lines and recurrent parent Huazhan

\begin{tabular}{|c|c|c|c|c|c|c|c|c|}
\hline Line & $\begin{array}{c}\text { Days from } \\
\text { seeding to } \\
\text { heading }\end{array}$ & $\begin{array}{c}\text { Plant height } \\
(\mathrm{cm})\end{array}$ & $\begin{array}{c}\text { Panicles per } \\
\text { plant }\end{array}$ & $\begin{array}{c}\text { Panicle } \\
\text { length }(\mathrm{cm})\end{array}$ & $\begin{array}{c}\text { Spikelet per } \\
\text { panicle }\end{array}$ & Seed set $(\%)$ & $\begin{array}{l}\text { 1000-grain } \\
\text { weight (g) }\end{array}$ & $\begin{array}{l}\text { yield per } \\
\text { plant (g) }\end{array}$ \\
\hline R43-01 & $88.7 \pm 1.2$ & $100.1 \pm 3.4^{* *}$ & $11.8 \pm 2.1$ & $22.6 \pm 0.8^{* *}$ & $160.4 \pm 12.5^{* *}$ & $90.5 \pm 1.8$ & $23.2 \pm 0.5^{* *}$ & $34.2 \pm 6.3$ \\
\hline R43-02 & $88.7 \pm 0.6$ & $99.9 \pm 2.9^{* * *}$ & $11.0 \pm 3.5$ & $22.2 \pm 0.7^{* *}$ & $152.3 \pm 13.6^{*}$ & $90.8 \pm 2.8$ & $25.2 \pm 0.3^{* *}$ & $34.1 \pm 12.4$ \\
\hline R43-03 & $89.0 \pm 1.0$ & $98.5 \pm 2.9^{* *}$ & $10.3 \pm 2.5$ & $22.5 \pm 1.1^{* *}$ & $154.3 \pm 15.4^{*}$ & $92.1 \pm 2.8$ & $23.2 \pm 0.2^{* *}$ & $33.8 \pm 7.6$ \\
\hline R43-04 & $88.3 \pm 0.6$ & $104.7 \pm 1.6^{* *}$ & $10.6 \pm 2.8$ & $22.1 \pm 1.2^{* *}$ & $171.0 \pm 25.5^{* *}$ & $87.7 \pm 5.0^{*}$ & $24.0 \pm 0.4^{* *}$ & $32.3 \pm 9.4$ \\
\hline R43-05 & $89.3 \pm 0.6$ & $100.1 \pm 2.5^{* *}$ & $13.2 \pm 3.4$ & $21.4 \pm 0.7^{* *}$ & $142.9 \pm 14.3$ & $90.2 \pm 4.2$ & $23.5 \pm 0.4^{* *}$ & $30.7 \pm 9.4$ \\
\hline R43-06 & $90.0 \pm 1.0$ & $102.3 \pm 2.6^{* *}$ & $11.2 \pm 4.3$ & $22.4 \pm 1.4^{* *}$ & $157.5 \pm 8.7^{* * *}$ & $88.3 \pm 5.6$ & $24.0 \pm 0.5^{* *}$ & $30.4 \pm 10.6$ \\
\hline R43-07 & $89.7 \pm 1.2$ & $100.3 \pm 4.0^{* * *}$ & $10.3 \pm 2.2$ & $22.1 \pm 1.1^{* *}$ & $142.0 \pm 23.7$ & $88.6 \pm 2.0$ & $24.6 \pm 0.6^{* *}$ & $28.5 \pm 6.4$ \\
\hline R43-08 & $89.3 \pm 0.6$ & $96.7 \pm 1.5^{*}$ & $11.0 \pm 2.6$ & $22.5 \pm 0.9^{* *}$ & $166.2 \pm 11.3^{* * *}$ & $85.9 \pm 4.3^{* *}$ & $23.6 \pm 0.4^{* *}$ & $32.8 \pm 6.7$ \\
\hline R43-09 & $88.7 \pm 0.6$ & $92.3 \pm 2.3$ & $13.6 \pm 2.2$ & $22.4 \pm 1.3^{* *}$ & $164.3 \pm 13.9^{* * *}$ & $86.4 \pm 3.6^{* *}$ & $23.5 \pm 0.4^{* *}$ & $38.0 \pm 7.8^{*}$ \\
\hline R43-10 & $90.3 \pm 0.6$ & $96.9 \pm 3.7^{*}$ & $11.6 \pm 2.3$ & $22.3 \pm 1.1^{* *}$ & $153.1 \pm 14.7^{*}$ & $90.8 \pm 2.8$ & $23.7 \pm 0.2^{* *}$ & $33.6 \pm 4.8$ \\
\hline $\mathrm{R} 43-11$ & $91.3 \pm 1.2^{*}$ & $100.9 \pm 3.6^{* *}$ & $9.9 \pm 2.5$ & $20.2 \pm 0.6$ & $143.1 \pm 20.5$ & $89.9 \pm 2.8$ & $25.9 \pm 0.7^{* *}$ & $28.6 \pm 9.3$ \\
\hline $\mathrm{R} 43-12$ & $88.0 \pm 1.0$ & $101.9 \pm 4.2^{* *}$ & $12.4 \pm 3.2$ & $22.1 \pm 0.5^{* *}$ & $147.9 \pm 15.6^{*}$ & $91.3 \pm 1.4$ & $25.0 \pm 0.5^{* *}$ & $34.5 \pm 7.0$ \\
\hline $\mathrm{R} 43-13$ & $89.3 \pm 0.6$ & $100.5 \pm 1.1^{* *}$ & $11.7 \pm 2.3$ & $20.7 \pm 0.6^{*}$ & $160.9 \pm 19.8^{* *}$ & $89.6 \pm 4.0$ & $22.2 \pm 0.5$ & $27.1 \pm 8.5$ \\
\hline $\mathrm{R} 43-14$ & $89.3 \pm 1.2$ & $99.0 \pm 5.6^{* *}$ & $11.1 \pm 2.8$ & $21.6 \pm 1.4^{* *}$ & $163.2 \pm 19.4^{* * *}$ & $86.7 \pm 3.9^{* *}$ & $23.2 \pm 0.6^{* *}$ & $30.0 \pm 5.2$ \\
\hline $\mathrm{R} 43-15$ & $89.3 \pm 0.6$ & $95.5 \pm 4.4$ & $11.7 \pm 3.8$ & $22.2 \pm 0.9^{* *}$ & $157.1 \pm 23.8^{* * *}$ & $91.0 \pm 2.4$ & $23.6 \pm 0.4^{* *}$ & $31.0 \pm 8.0$ \\
\hline Huazhan & $89.3 \pm 0.6$ & $93.2 \pm 3.3$ & $12.0 \pm 2.1$ & $19.6 \pm 0.5$ & $129.4 \pm 21.3$ & $91.8 \pm 1.9$ & $21.7 \pm 0.2$ & $27.9 \pm 4.1$ \\
\hline
\end{tabular}

All agronomic traits data were mean of three plants over three replicates. * and ** mean significant difference at 0.05 and 0.01 level respectively. 
Table 4 Comparison of agronomic traits between fifteen improved hybrids and the control hybrid Tianyouhuazhan

\begin{tabular}{|c|c|c|c|c|c|c|c|c|}
\hline Hybrid & $\begin{array}{c}\text { Days from } \\
\text { seeding to } \\
\text { heading }\end{array}$ & $\begin{array}{c}\text { Plant height } \\
\text { (cm) }\end{array}$ & $\begin{array}{c}\text { Panicles per } \\
\text { plant }\end{array}$ & $\begin{array}{c}\text { Panicle } \\
\text { length }(\mathrm{cm})\end{array}$ & $\begin{array}{c}\text { Spikelet per } \\
\text { panicle }\end{array}$ & Seed set $(\%)$ & $\begin{array}{l}\text { 1000-grain } \\
\text { weight (g) }\end{array}$ & $\begin{array}{l}\text { yield per } \\
\text { plant (g) }\end{array}$ \\
\hline TianfengA/R43-01 & $83.3 \pm 0.6$ & $108.9 \pm 3.6$ & $10.2 \pm 1.6$ & $23.9 \pm 1.2$ & $178.9 \pm 19.8$ & $87.1 \pm 3.6$ & $26.9 \pm 0.3^{* *}$ & $36.4 \pm 9.3$ \\
\hline TianfengA/R43-02 & $84.0 \pm 1.0$ & $107.4 \pm 3.0$ & $10.6 \pm 2.2$ & $23.8 \pm 1.6$ & $167.6 \pm 26.7$ & $82.5 \pm 5.1$ & $28.3 \pm 0.2^{* *}$ & $38.5 \pm 12.3$ \\
\hline TianfengA/R43-03 & $83.3 \pm 0.6$ & $106.4 \pm 3.5$ & $11.0 \pm 1.0$ & $22.9 \pm 1.1$ & $178.0 \pm 22.5$ & $86.2 \pm 2.8$ & $27.7 \pm 0.5^{* *}$ & $39.4 \pm 6.7$ \\
\hline TianfengA/R43-04 & $82.7 \pm 1.2$ & $110.1 \pm 3.1$ & $12.0 \pm 3.0$ & $22.5 \pm 0.6$ & $154.8 \pm 18.5^{*}$ & $86.4 \pm 4.8$ & $28.0 \pm 0.6^{* *}$ & $35.4 \pm 7.9$ \\
\hline TianfengA/R43-05 & $83.7 \pm 0.6$ & $109.2 \pm 2.5$ & $11.6 \pm 1.9$ & $23.5 \pm 1.9$ & $175.6 \pm 29.9$ & $84.8 \pm 6.3$ & $27.0 \pm 0.3^{* *}$ & $40.2 \pm 7.4$ \\
\hline TianfengA/R43-06 & $84.3 \pm 0.6$ & $112.2 \pm 3.5$ & $11.1 \pm 1.8$ & $23.6 \pm 1.2$ & $181.8 \pm 26.6$ & $84.0 \pm 3.4$ & $27.6 \pm 0.3^{* *}$ & $38.6 \pm 8.4$ \\
\hline TianfengA/R43-07 & $83.7 \pm 1.2$ & $109.0 \pm 2.3$ & $11.3 \pm 2.0$ & $23.1 \pm 1.1$ & $165.7 \pm 23.6$ & $82.6 \pm 3.9$ & $27.5 \pm 0.4^{* *}$ & $36.8 \pm 10.9$ \\
\hline TianfengA/R43-08 & $83.3 \pm 0.6$ & $108.2 \pm 7.0$ & $11.8 \pm 1.6$ & $23.2 \pm 1.2$ & $167.3 \pm 19.8$ & $84.9 \pm 4.1$ & $27.8 \pm 0.7^{* *}$ & $39.4 \pm 8.9$ \\
\hline TianfengA/R43-09 & $82.7 \pm 0.6$ & $107.1 \pm 3.9$ & $12.1 \pm 1.3$ & $23.9 \pm 0.9$ & $176.6 \pm 22.4$ & $85.7 \pm 1.3$ & $28.0 \pm 0.3^{* *}$ & $43.1 \pm 7.9$ \\
\hline TianfengA/R43-10 & $83.3 \pm 0.6$ & $109.4 \pm 3.7$ & $11.3 \pm 2.1$ & $23.5 \pm 1.2$ & $168.1 \pm 28.4$ & $84.9 \pm 2.8$ & $27.7 \pm 0.2^{* *}$ & $40.9 \pm 11.7$ \\
\hline TianfengA/R43-11 & $85.7 \pm 1.2^{* *}$ & $118.2 \pm 4.5^{* * *}$ & $12.0 \pm 1.7$ & $23.5 \pm 1.6$ & $185.8 \pm 36.6$ & $81.3 \pm 3.6$ & $29.1 \pm 0.7^{* *}$ & $49.5 \pm 12.1$ \\
\hline TianfengA/R43-12 & $82.7 \pm 0.6$ & $113.4 \pm 2.8^{*}$ & $11.6 \pm 2.2$ & $23.9 \pm 1.2$ & $173.1 \pm 22.9$ & $87.7 \pm 3.5$ & $27.8 \pm 0.2^{* *}$ & $42.8 \pm 10.2$ \\
\hline TianfengA/R43-13 & $83.7 \pm 0.6$ & $105.9 \pm 5.1$ & $11.8 \pm 1.1$ & $23.9 \pm 1.1$ & $168.0 \pm 26.0$ & $85.0 \pm 4.5$ & $27.0 \pm 0.4^{* *}$ & $40.8 \pm 8.2$ \\
\hline TianfengA/R43-14 & $83.0 \pm 1.0$ & $109.7 \pm 4.1$ & $10.6 \pm 4.0$ & $23.8 \pm 1.3$ & $185.0 \pm 29.7$ & $80.5 \pm 10.5$ & $26.7 \pm 0.8^{* *}$ & $37.9 \pm 17.5$ \\
\hline TianfengA/R43-15 & $84.0 \pm 1.0$ & $107.8 \pm 3.2$ & $11.7 \pm 1.2$ & $23.4 \pm 0.6$ & $166.3 \pm 17.4$ & $85.1 \pm 2.6$ & $27.6 \pm 0.3^{* *}$ & $42.1 \pm 8.1$ \\
\hline Tianyouhuazhan & $83.7 \pm 0.6$ & $108.7 \pm 3.1$ & $11.4 \pm 3.4$ & $23.2 \pm 0.9$ & $192.1 \pm 28.5$ & $85.0 \pm 4.0$ & $25.9 \pm 0.4$ & $39.8 \pm 10.9$ \\
\hline
\end{tabular}

All agronomic traits data were mean of three plants over three replicates. * and ** mean significant difference at 0.05 and 0.01 level respectively. 
According to the results of plot yield test in 2013, only three hybrid combinations TianfengA/R43-06, TianfengA/R43-13 and TianfengA/R43-10 increased in GYP by 3.04\%, 2.15\% and $1.90 \%$ respectively (Fig.6a), but the increases over control hybrid Tianyouhuazhan were not significant (P>0.05). In 2014, eight combinations (TianfengA/R43-07, TianfengA/R43-05, TianfengA/R43-04, TianfengA/R43-01, TianfengA/R43-08, TianfengA/R43-09, TianfengA/R43-11 and TianfengA/R43-06) showed increases in GYP over Tianyouhuazhan, among which the TianfengA/R43-07 had the highest increase in GYP $(+6.7 \%)$, but the increase was not significant when comparing with the control (Fig.6b). Based on the integrated results of GYP in two years, two improved hybrids TianfengA/R43-06 and TianfengA/R43-07 had constantly higher GYP than the control Tianyouhuazhan and other improved hybrids. In consideration of R or HR level of resistance to both BB and BPH of these two hybrid combinations, the hybrids TianfengA/R43-06 and TianfengA/R43-07 were considered as two promising hybrid combinations.
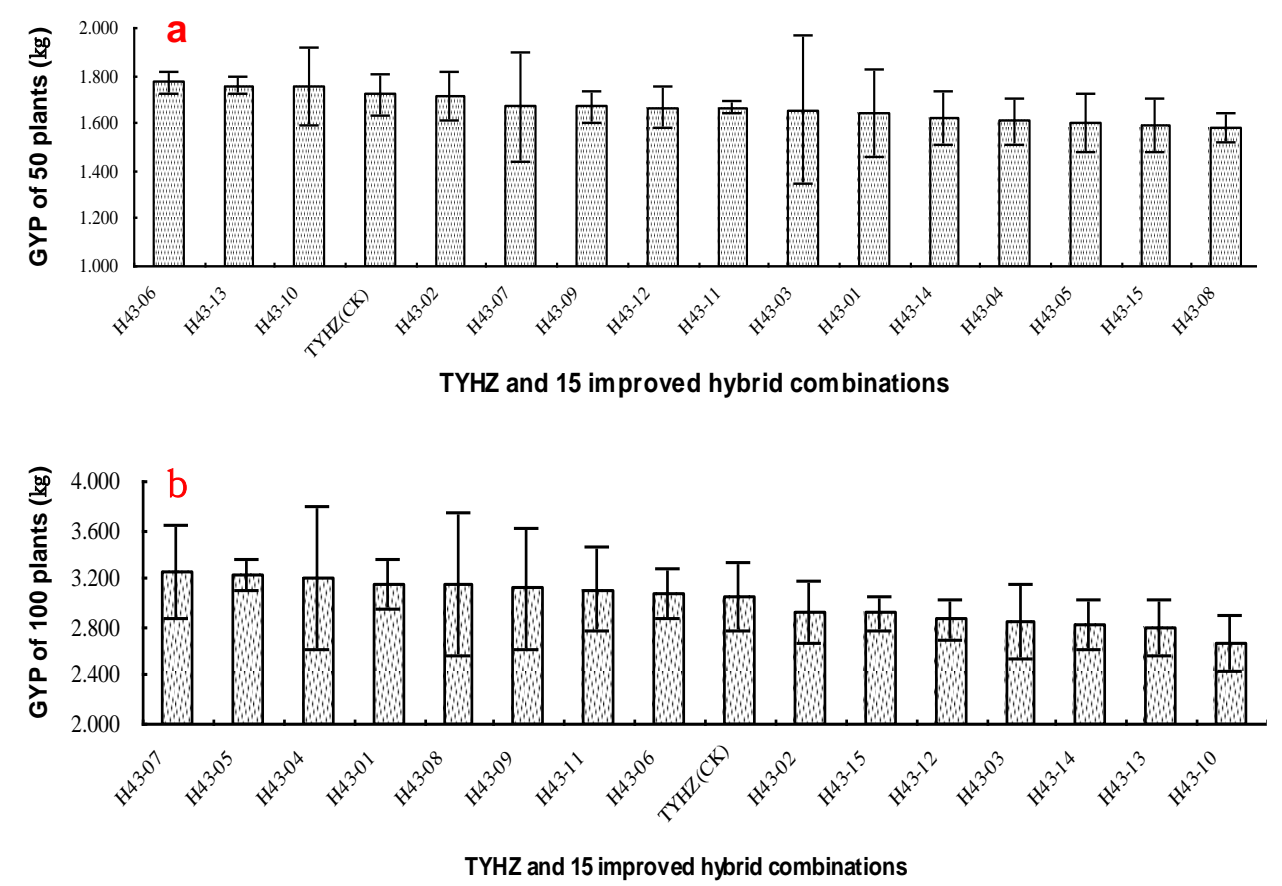

Fig.6 Comparison of GYP amongst fifteen improved hybrid combinations and Tianyouhuazhan in 2013 and 2014. (a) Comparison of GYP of 50 plants per plot in 2013. (b) Comparison of GYP of 100 plants 
per plot in 2014. TYHZ stands for the control hybrid Tianyouhuazhan. H43-01 H43-15 represent the fifteen improved hybrids TianfengA/R43-01 TianfengA/R43-15 respectively. GYP: grain yield per plot.

\section{Discussion}

Gene pyramiding has been used not only to breed broad-spectrum and durable resistant varieties by assembling multiple resistance genes for one trait, but also to develop multiple resistant rice varieties by stacking multiple resistance genes for different traits (Zhan et al. 2012; Hari et al. 2013; Pan et al. 2013). 9311 and Minghui63 were two main restorer lines greatly used in hybrid rice production in China in the past twenty years (Xie et al. 1996; Deng 2005; Zou et al. 2008). Hybrid combinations from 9311 and Minghui63 had high yield potential and wide adaptability, but were susceptible to main diseases and insects (Xie et al. 1996; Deng 2005; Zou et al. 2008). To date, it was reported that $\mathrm{BB}$ and $\mathrm{BPH}$ resistance of these two restorer lines and their hybrids were improved by MABC coupled with phenotypic selection respectively (Zhou et al. 2003; Zhang et al. 2006; Hu et al. 2012; Hu et al. 2013), but the yield potential and grain quality of hybrids from these two restorer lines were limited due to release more than twenty years ago. Huazhan is an elite male parent in the current rice production, and its hybrid combination Tianyouhuazhan have high yield potential, wide adaptability and good grain quality, but are susceptible to BB and BPH (Yu et al. 2009; Li et al. 2012). So far there are no reports about simultaneous improvement of BB and BPH resistance of Huazhan and its hybrids. In this study, one BB resistant gene (Xa23) and two BPH resistant genes (Bph14 and Bph15) were simultaneously pyramided into Huazhan through MABC strategy over four years (Fig.1), and a series of improved restorer lines and their hybrids with excellent agronomic traits and superior resistance to both $\mathrm{BB}$ and $\mathrm{BPH}$ were obtained (Table 1; Table 2; Fig.4; Fig.5). Furthermore, TianfengA/R43-06 and TianfengA/R43-07 with higher yield potential and stronger resistance to both 
BB and BPH than the control hybrid Tianyouhuazhan and other improved hybrids were selected out as two promising hybrid combinations (Fig.6).

Molecular improvement of $\mathrm{BB}$ resistance focused on conventional varieties and hybrid rice parental lines. Zhou et al. (2003) introgressed Xa21 gene into a restorer line 9311 and obtained an improved restorer line and its hybrids which showed MR or R level of resistance to BB. Ding (2005) developed new hybrid combinations carrying $\mathrm{Xa}$ gene with high resistance to BB. Zhang et al. (2006) used MAS for pyramiding $\mathrm{Xa} 7$ and $\mathrm{Xa} 21$ into Minghui63. The results of BB resistance identification showed that the improved Minghui63 and its hybrids were very highly resistant to ten Xoo strains, but susceptible to PXO99 (Race P6). Zeng et al. (2009) obtained a conventional variety Baixiangzhan containing $x a 5$ gene with high resistance to V pathotype. Sundaram et al. $(2008,2009)$ pyramided xa5, xa13 and Xa21 genes into Samba Mahsuri and Triguna, and developed improved varieties with significantly higher resistance to BB than the original versions. Suh et al. (2013) obtained improved Mangeumbyeo lines carrying $\mathrm{Xa4}$, $x a 5$ and $\mathrm{Xa21}$ genes, which showed HR level of resistance to BB. Win et al. (2013) simultaneously incorporated $x a 5, \mathrm{Xa21}$ and $x a 33$ into a high quality and aromatic variety MK-75, and obtained improved lines with high resistance to BB. However, among BB resistance genes greatly used in rice breeding, $x a 5$ and $x a 13$ are recessive genes that are difficult to apply in hybrid rice breeding. Xa4 gene has incomplete dominance nature and its resistance level is affected by the genetic background. Xa21 gene generally expresses resistance at late tillering stage, and its resistance level is also affected by the genetic background. $\mathrm{Xa7}$ gene cannot confer resistance to PXO99 strain. Xa23 gene will have greater application prospect in breeding BB resistant hybrid rice because this gene has broad spectrum resistance, and shows very high level resistance over all the growth stage (Zhang et al. 1998, 2001). Li et al. (2006a) and Zhou et al. (2011) respectively introduced 
Xa23 gene to two popular restorer lines 9311 and Minghui63. These improved restorer lines and their hybrids exhibited HR or R level of resistance to all Xoo strains from China, India, Philippines and Japan, suggesting that the expression of $\mathrm{Xa23}$ gene is not affected by genetic background of recipient. In this study, we found that fifteen improved restorer lines and their hybrids with $\mathrm{Xa23}$ gene were highly resistant to all twelve strains belonging to different pathotypes from China and Philippines (Table 1; Table 2), that further indicated the genetic background could not affect the function of $X a 23$ gene, and demonstrated the great application value of $\mathrm{Xa23}$ gene. The next step towards the utilization of BB-resistant restorer lines and their hybrids carrying Xa23 will be playing a crucial role in controlling BB in China and other Asian countries.

IRRI was the earliest research institute of carrying out molecular breeding of BPH resistance, and developed BPH-resistant varieties IR26, IR36, IR56 and IR66, which harbored Bph1, bph2, Bph3 and bph4 respectively (Cruz et al. 2011; Deng et al. 2011) and were used intensively in southeast Asia. Then, Sharma et al. (2004) obtained new japonica lines carrying Bphl and bph2 with resistance to BPH. Results of BPH bioassays showed that the pyramided lines with two resistance genes were more significantly resistant to BPH than those with single resistant gene. China began to implement molecular breeding of BPH resistance at beginning of this century. Yang et al. (2010) and Liu et al. (2013) introgressed Bph3 and Bph24 into maintainer lines and restorer lines respectively, and the improved lines showed significantly higher resistance to BPH than their original parents. Qiu et al. (2012) developed improved Nipponbare lines carrying Bph6 and Bph12, which showed R or HR level of resistance to BPH. Hu et al. (2012, 2013) obtained improved Minghui63, improved 9311 and their hybrids carrying both Bph14 and Bph15 gene using MABC strategy. BPH bioassay found out that the improved restorer lines with homozygous Bphl4 and Bph15 gene showed higher level of resistance 
than their hybrids. In consideration of biosafety and biodiversity, the utilization of Bph14 and Bph15 gene in rice breeding was limited in China (Fujita et al. 2013). Numerous studies revealed that the BPH resistance level conferred by Bph14 and Bph15 gene was related to genetic background of recipient. The improved 9311 carrying homozygous Bph14 and Bph15 had slightly higher or similar resistance to $\mathrm{BPH}$ than the heterozygous genotypes, suggesting that these two genes were of almost dominance or dominance on background of 9311 (Hu et al. 2013) . Hu et al. (2012) also found that the Bphl4 and Bph15 genes were of incomplete dominance on background of Minghui63. Yan et al. (2014) reported that the improved restorer line carrying homozygous Bphl4 and Bph15 gene had high resistance to $\mathrm{BPH}$, but its hybrids derived from this improved line were highly susceptible to BPH, suggesting that the Bph14 and Bph15 gene were not dominant on background of R1005. In this study, fifteen improved restorer lines and their hybrids displayed HR or R level to BPH except hybrid TianfengA/R43-09 displayed MR level; generally speaking, the resistance levels of hybrids heterozygous on Bph14 and Bph15 gene fluctuated up or down around the resistance levels of corresponding restorer lines homozygous on Bph14 and Bph15 gene (Fig.4; Fig.5). That fortunately indicates these two genes are of dominance on genetic background of Huazhan. However, the improved restorer lines and their hybrids were evaluated on BPH resistance only at seedlings stage in this study, and it is still unknown about adult-plant resistance to BPH of these improved lines and hybrids. So the BPH resistance of adult-plant or field resistance of these improved lines and hybrids needs to be evaluated in the future.

In order to develop new rice variety with strong resistance to diseases and insects, good grain quality and high yield potential, it is needed to evaluate agronomic traits of improved lines on the process of improving insects and diseases resistance. Sundaram et al. (2008) showed that the improved Samba Mahsuri carrying $x a 5, x a 13$ and $\mathrm{Xa21}$ was superior or similar in agronomic traits to Samba 
Mahsuri. Hu et al. (2012) suggested that the agronomic traits of improved Minghui63 and its hybrids were superior or similar to those of Minghui63 and its hybrids. The improved 9311 and R1005 carrying two or three BPH resistance genes were also superior or similar in agronomic traits to 9311 and R1005 respectively, but the agronomic traits of their hybrids were not evaluated (Hu et al. 2013; Yan et al. 2014). Chen et al. (2013) also obtained the improved Zhehui7954 and its hybrids pyramiding Xa23 and Bph18 that their agronomic traits were superior or similar to the original version. In this study, the introgression of $\mathrm{BB}$ and $\mathrm{BPH}$ resistance genes into the elite restorer line Huazhan does not bring apparent yield penalty. Conversely, the 1000-grain weight of improved restorer lines and their hybrids are significantly heavier $(\mathrm{P}<0.01)$ than those of Huazhan and Tianyouhuazhan respectively (Table 3 ; Table 4), demonstrating that the yield potential was increased after improvement. We are believed that the BB and BPH resistant hybrids developed in this study will be of great advantage in BB and/or BPH endemic areas.

\section{Conclusion}

Fifteen improved restorer lines, designated as R43-01 R43-15, have been developed by introgressing one BB resistance gene Xa23 and two BPH resistance genes Bph14 and Bph15 into an elite restorer line Huazhan through MABC and phenotypic selection approaches. Bioassays indicate that the fifteen pyramided lines and their hybrids are obviously improved in both BB and BPH resistance comparing with those of their respective original versions. Two improved hybrid combinations TianfengA/R43-06 and TianfengA/R43-07 are selected out from fifteen improved hybrids due to higher yield potential and broader-spectrum and stronger resistance to both BB and BPH than Tianyouhuazhan.

\section{Acknowledgments}

This study was supported by the Knowledge Innovation Program of Chinese Academy of Sciences (KCX2-EW-N-01).The author thanks for the help of Dr. Hui Wei from National Renewable Energy Laboratory, 
Department of Energy, USA in revision of this paper.

\section{References}

Cao, L., Zhuang, J., Yuan, S., Zhan, X., Zheng, K., Cheng, S., 2003. Hybrid rice resistant to bacterial leaf blight developed by marker assisted selection. Rice Sci 17, 184-186.

Chen, K., Zhang, Q., Pan, X., Li, M., Meng, L., Xu, Z., Xu, J., Li, Z., 2013. Evaluation of Effect of Resistance Improvement of Bacterial Leaf Blight and Brown Planthopper for Three Dominant Indica Restorer Lines. Acta Agro Sin 39, 409-422.

Chen, Z., Li, C., Sun, Y., Chen, K., Li, S., 2006. Characteristic and Application of A Three-Line Sterile Line of Indica type rice TianfengA. Guangdong Agr Sci 9, 54-55.

Cheng, X.Y., Zhu, L.L., He, G.C., 2013. Towards Understanding of Molecular Interactions between Rice and the Brown Planthopper. Mol Plant 6, 621-634.

Cruz, A.P., Arida, A., Heong, K.L., Horgan, F.G., 2011. Aspects of brown planthopper adaptation to resistant rice varieties with the Bph3 gene. Entomol Exp Appl 141, 245-257.

Deng, F., Ni, S., Zhu, X., 2011. Present Status and Prospect of Breeding Resistant Cultivars of Brown Planthopper in Rice. Chinese Agr Sci Bul 27, 229-237.

Deng, Q., 2005. Breeding of the PTGMS Line Y58S with Wide Adaptability in Rice. Hybrid Rice 20, 15-18.

Ding, L., 2005. Breeding of Hybrid Rice Combinations Highly Resistant to Bacterial Leaf Blight. Hybrid Rice 20, $11-14$.

Du, B., Zhang, W.L., Liu, B.F., Hu, J., Wei, Z., Shi, Z.Y., He, R.F., Zhu, L.L., Chen, R.Z., Han, B., He, G.C., 2009. Identification and characterization of Bph14, a gene conferring resistance to brown planthopper in rice. P Natl Acad Sci USA 106, 22163-22168.

Fujita, D., Kohli, A., Horgan, F.G., 2013. Rice Resistance to Planthoppers and Leafhoppers. Crit Rev Plant Sci 32, 162-191.

Gao, L., Gao, H., Li, R., Li, D., Zhou, M., Yan, Q., Zhou, W., Zhang, J., Deng, G., 2010. Optimization and Verification of Molecular Markers for Rice Bacteial Blight Resistance Gene Xa23. Mol Plant Breed 8, 660-664.

Hari, Y., Srinivasarao, K., Viraktamath, B.C., Prasad, A.S.H., Laha, G.S., Ahmed, M.I., Natarajkumar, P., Sujatha, K., Prasad, M.S., Pandey, M., Ramesha, M.S., Neeraja, C.N., Balachandran, S.M., Rani, N.S., Kemparaju, B., Mohan, K.M., Sama, V.S.A.K., Shaik, H., Balachiranjeevi, C., Pranathi, K., Reddy, G.A., Madhav, M.S., 
Sundaram, R.M., 2013. Marker-assisted introgression of bacterial blight and blast resistance into IR 58025B, an elite maintainer line of rice. Plant Breeding 132, 586-594.

He, L., Gao, L., Wang, Z., Deng, G., Cen, Z., Yan, Q., Hang, J., Gao, H., 2011. Screening of Effective Resistance Genes and Resistant Rice Parents against Rice Bacterial Blight. Plant Dis Pest 2, 18-20.

Hu, J., Cheng, M.X., Gao, G.J., Zhang, Q.L., Xiao, J.H., He, Y., 2013. Pyramiding and evaluation of three dominant brown planthopper resistance genes in the elite indica rice 9311 and its hybrids. Pest management science $69,802-808$.

Hu, J., Li, X., Wu, C.J., Yang, C.J., Hua, H.X., Gao, G.J., Xiao, J.H., He, Y.Q., 2012. Pyramiding and evaluation of the brown planthopper resistance genes Bph14 and Bph15 in hybrid rice. Mol Breeding 29, 61-69.

Huang, B., Xu, J.Y., Hou, M.S., Ali, J., Mou, T.M., 2012. Introgression of bacterial blight resistance genes Xa7, Xa21, Xa22 and Xa23 into hybrid rice restorer lines by molecular marker-assisted selection. Euphytica 187, 449-459.

Huang, D., Qiu, Y., Zhang, Y., Huang, F., Meng, J., Wei, S., Li, R., Chen, B., 2013. Fine mapping and characterization of $\mathrm{BPH} 27$, a brown planthopper resistance gene from wild rice (Oryza rufipogon Griff.). Theor Appl Genet 126, 219-229.

Huang, S., Huang, F., Wu, B., Long, L., Ling, Y., 2014. Studies on biotypes of the brown and white-backed planthopper in China and Vietnam. Chinese J Appl Entomol 51, 525-533.

Huang, Z., He, G., Shu, L., Li, X., Zhang, Q., 2001. Identification and mapping of two brown planthopper resistance genes in rice. Theor Appl Genet 102, 929-934.

Jena, K.K., Kim, S.M., 2010. Current Status of Brown Planthopper (BPH) Resistance and Genetics. Rice 3, $161-171$

Khan, M.A., Naeem, M., Iqbal, M., 2014. Breeding approaches for bacterial leaf blight resistance in rice (Oryza sativa L.), current status and future directions. Eur J Plant Pathol 139, 27-37.

Li, J., Wan, B., Xia, M., Qi, H., Shi, H., Xin, F., 2011. Breeding of the brown planthopper resistant rice varieties. Chinese J Appl Entomol 48, 1348-1353.

Li, J., Wang, C., Xia, M., Zhao, K., Qi, H., Wan, B., Zha, Z., Lu, X., 2006a. Enhancing Bacterial Blight Resistance of Hybrid Rice Restorer Lines through Marker-Assisted Selection of the Xa23 Gene. Acta Agro Sin 32, 1423-1429.

Li, J., Xia, M., Qi, H., He, G., Wan, B., Zha, Z., 2006b. Marker-Assisted Selection for Brown Planthopper (Nilaparvata lugens Stå1) Resistance Genes Bph14 and Bph15 in Rice. Sci Agr Sin 39, 2132-2137. 
Li, Y., Xiao, L., Yuan, X., Wen, S., Zhong, J., Zhong, M., 2012. Characteristics and High-yielding Cultivation Techniques of New Indica Late Hybrid Rice Combination TianyouHuazhan. Bul Agr Sci Technol 3, 104-105.

Lin, Y., Yang, B., Zeng, Q., Du, J., 2014a. Breeding and Application of a New Hybrid Rice Combination Xinrongyouhuazhan. China Rice 20, 76-77.

Lin, Y., Yang, B., Zeng, Q., Du, J., 2014b. C-Liang-you-Hua-zhan, a New Two-line Medium Hybrid Rice Combination with High Yield and Good Quality. Hybrid Rice 29, 76-77.

Liu, G., Fu, Z., Shen, J., Zhang, Y., 2002. Comparative study on evaluation methods for resistance to rice plan thopper and (Homopetra: Delphacidae) in rice. Chinese J Rice Sci 16, 52-56.

Liu, H., Liu, F., Hu, B., Yang, W., Chen, Z., Xu, Z., 2004. Virulence of Xanthomonas oryzae pv.oryzae on ce Near-lsogenic Lines with Single Resistance Gene and Pyramiding Lines in China. Agr Sci China 3, 764-769.

Liu, H., Yang, W., Hu, B., Liu, F., 2007. Virulence analysis and race classification of Xanthomonas oryzae pv. oryzae in China. J Phytopathol 155, 129-135.

Liu, K., Zhang, Y., Liu, F., Qiu, Y., Feng, J., Huang, F., Wu, B., Li, Z., Chen, Y., Wei, S., Cen, Z., Qin, B., Wei, M., Wei, Z., Li, R., 2013. Resistant Performance of Bacterial Blight and Brown Planthopper Resistance Gene-Pyramided Lines in Rice. Southwest China J Agr Sci 26, 1852-1857.

Liu, Y., Wu, H., Chen, H., Liu, Y., He, J., Kang, H., Sun, Z., Pan, G., Wang, Q., Hu, J., Zhou, F., Zhou, K., Zheng, X., Ren, Y., Chen, L., Wang, Y., Zhao, Z., Lin, Q., Wu, F., Zhang, X., Guo, X., Cheng, X., Jiang, L., Wu, C., Wang, H., Wan, J., 2015. A gene cluster encoding lectin receptor kinases confers broad-spectrum and durable insect resistance in rice. Nat Biotech 33, 301-305.

Mew, T.W., Alvarez, A.M., Leach, J.E., Swings, J., 1993. Focus on Bacterial-Blight of Rice. Plant Dis 77, 5-12.

Pan, X., Chen, K., Zhang, Q., Huang, S., Xie, L., Li, M., Meng, L., Xu, Z., Xu, J., Li, Z., 2013. Developing Restorer Lines Pyramiding Different Resistant Genes to Blast and Bacterial Leaf Blight by Marker-assisted Selection in Rice. Acta Agro Sin 39, 1582-1593.

Perez, L.M., Redona, E.D., Mendioro, M.S., Cruz, C.M.V., Leung, H., 2008. Introgression of Xa4, Xa7 and Xa21 for resistance to bacterial blight in thermosensitive genetic male sterile rice (Oryza sativa L.) for the development of two-line hybrids. Euphytica 164, 627-636.

Qiu, Y.F., Guo, J.P., Jing, S.L., Zhu, L.L., He, G.C., 2012. Development and characterization of japonica rice lines carrying the brown planthopper-resistance genes BPH12 and BPH6. Theor Appl Genet 124, 485-494.

Rao, Y.C., Li, Y.Y., Qian, Q., 2014. Recent progress on molecular breeding of rice in China. Plant Cell Rep 33, $551-564$. 
Sharma, P.N., Torii, A., Takumi, S., Mori, N., Nakamura, C., 2004. Marker-assisted pyramiding of brown planthopper (Nilaparvata lugens Stål) resistance genes Bph1 and Bph2 on rice chromosome 12. Hereditas 140, 61-69.

Singh, S., Sidhu, J.S., Huang, N., Vikal, Y., Li, Z., Brar, D.S., Dhaliwal, H.S., Khush, G.S., 2001. Pyramiding three bacterial blight resistance genes (xa5, xa13 and Xa21) using marker-assisted selection into indica rice cultivar PR106. Theor Appl Genet 102, 1011-1015.

Suh, J.P., Jeung, J.U., Noh, T.H., Cho, Y.C., Park, S.H., Park, H.S., Shin, M.S., Kim, C.K., Jena, K.K., 2013. Development of breeding lines with three pyramided resistance genes that confer broad-spectrum bacterial blight resistance and their molecular analysis in rice. Rice 6.

Sundaram, R.M., Vishnupriya, M.R., Biradar, S.K., Laha, G.S., Reddy, G.A., Rani, N.S., Sarma, N.P., Sonti, R.V., 2008. Marker assisted introgression of bacterial blight resistance in Samba Mahsuri, an elite indica rice variety. Euphytica 160, 411-422.

Sundaram, R.M., Vishnupriya, M.R., Laha, G.S., Rani, N.S., Rao, P.S., Balachandran, S.M., Reddy, G.A., Sarma, N.P., Sonti, R.V., 2009. Introduction of bacterial blight resistance into Triguna, a high yielding, mid-early duration rice variety. Biotechnology journal 4, 400-407.

Tamura, Y., Hattori, M., Yoshioka, H., Yoshioka, M., Takahashi, A., Wu, J.Z., Sentoku, N., Yasui, H., 2014. Map-based Cloning and Characterization of a Brown Planthopper Resistance Gene BPH26 from Oryza sativa L. ssp indica Cultivar ADR52. Sci Rep-Uk 29, 5872.

Tian, D.S., Wang, J.X., Zeng, X., Gu, K.Y., Qiu, C.X., Yang, X.B., Zhou, Z.Y., Goh, M.L., Luo, Y.C., Murata-Hori, M., White, F.F., Yin, Z.C., 2014. The Rice TAL Effector-Dependent Resistance Protein XA10 Triggers Cell Death and Calcium Depletion in the Endoplasmic Reticulum. Plant Cell 26, 497-515.

Vera Cruz, C.M., Bai, J.F., Ona, I., Leung, H., Nelson, R.J., Mew, T.W., Leach, J.E., 2000. Predicting durability of a disease resistance gene based on an assessment of the fitness loss and epidemiological consequences of avirulence gene mutation. P Natl Acad Sci USA 97, 13500-13505.

Wang, C.L., Zhang, X.P., Fan, Y.L., Gao, Y., Zhu, Q.L., Zheng, C.K., Qin, T.F., Li, Y.Q., Che, J.Y., Zhang, M.W., Yang, B., Liu, Y.G., Zhao, K.J., 2015. XA23 Is an Executor R Protein and Confers Broad-Spectrum Disease Resistance in Rice. Mol Plant 8, 290-302.

Webb, K.M., Ona, I., Bai, J., Garrett, K.A., Mew, T., Cruz, C.M.V., Leach, J.E., 2010. A benefit of high temperature: increased effectiveness of a rice bacterial blight disease resistance gene. New Phytol 185, 568-576. 
Win, K.M., Korinsak, S., Sirithunya, P., Lanceras-Siangliw, J., Jamboonsri, W., Da, T., Patarapuwadol, S., Toojinda, T., 2013. Marker assisted introgression of multiple genes for bacterial blight resistance into aromatic Myanmar rice MK-75. Field Crop Res 154, 164-171.

Wu, H., Liu, Y.Q., He, J., Liu, Y.L., Jiang, L., Liu, L.L., Wang, C.M., Cheng, X.N., Wan, J.M., 2014. Fine mapping of brown planthopper (Nilaparvata lugens Stål) resistance gene Bph28(t) in rice (Oryza sativa L.). Mol Breeding 33, 909-918.

Wu, X.M., Li, Y.R., Zou, L.F., Chen, G.Y., 2007. Gene-for-gene relationships between rice and diverse avrBs3/pthA avirulence genes in Xanthomonas oryzae pv. oryzae. Plant Pathol 56, 26-34.

Xia, M., Wan, B., Li, J., Zha, Z., Du, X., Qi, H., 2010. Breeding and Application of New Quality Medium Indica Hybrid Rice Combination Guangliangyou476. Hybrid Rice 25, 18-20.

Xie, H., Zheng, J., Zhang, S., Lin, M., 1996. Breeding Theory and Practice of "Shanyou 63" the Variety with the Largest Cultivated Area in China. J Fujian Acad Agr 11, 1-6.

Xu, J., 2013. Breeding of Three-line Indica Late Hybrid Rice combination Rongyouhuazhan. Guangdong Agr Sci 1, 11-12.

Xu, J., Lin, G., 2013. Characteristics and Cultivation Techniques of New Three-line Late Hybrid Rice Combination Yueyouhuazhan. Seed 32, 114-115.

Yan, C., Mamadou, G., Zhu, Z., Mou, T., 2014. Improving the brown planthopper resistance of rice restorer line R1005 with molecular marker-assisted selection. J Huazhong Agr Univ 33, 8-14.

Yang, H., Wei, S., Li, X., Zhang, Y., Liu, C., Chen, Q., Cen, Z., Wei, S., Yang, L., Huang, F., He, W., Liu, K., Huang, D., Ma, Z., Huang, Y., Song, J., Li, R., 2010. Rice Pyramiding Lines Conferring Resistances to Brown Planthopper and Bacterial Leaf Blight by Marker-Assisted Selection. Mol Plant Breed 8, 11-19.

Yang, H.Y., You, A.Q., Yang, Z.F., Zhang, F., He, R.F., Zhu, L.L., He, G., 2004. High-resolution genetic mapping at the Bph15 locus for brown planthopper resistance in rice (Oryza sativa L.). Theor Appl Genet 110, 182-191.

Yu, S., Zhu, L., Ouyang, Y., Xu, D., Zhu, X., Jin, Q., 2009. Characteristics and High-yielding Cultivation Techniques of New Hybrid Rice Combination Tianyouhuazhan. Hybrid Rice 24, 42-44.

Yuan, L., 2014. Development of Hybrid Rice to Ensure Food Security. Rice Sci 21, 1-2.

Zeng, L., Cheng, T., Zhu, X., Chen, S., Yang, J., Kong, D., Yang, Q., 2009. Development of the first BB-resistant rice variety Baixiangzhan with high resistance to V pathotype. Guangdong Agr Sci 5, 19-20.

Zeng, L., Huang, S., Wu, S., 2002. The resistance of IRBB21 (Xa21) against 5 races of Guangdong province. Acta Phytopathol Sin 29, 97-100. 
Zhan, X., Zhou, H., Chai, R., Zhuang, J., Cheng, S., Cao, L., 2012. Breeding of R8012, a Rice Restorer Line Resistant to Blast and Bacterial Blight Through Marker-Assisted Selection. Rice Sci 19, 29-35.

Zhang, F., Zhuo, D.L., Zhang, F., Huang, L.Y., Wang, W.S., Xu, J.L., Cruz, C., Li, Z.K., Zhou, Y.L., 2015. Xa39, a novel dominant gene conferring broad-spectrum resistance to Xanthomonas oryzae pv. oryzae in rice. Plant Pathol 64, 568-575.

Zhang, J., Li, X., Jiang, G., Xu, Y., He, Y., 2006. Pyramiding of Xa7 and Xa21 for the improvement of disease resistance to bacterial blight in hybrid rice. Plant Breeding 125, 600-605.

Zhang, Q., 2009. Genetic and Improvement of Resistance to Bacterial Blight in Hybrid Rice in China. Chinese J Rice Sci 23, 111-119.

Zhang, Q., Lin, S., Zhao, B., Wang, C., Yang, W., Zhou, Y., Li, D., Chen, C., Zhu, L., 1998. Identification and tagging a new gene for resistance to bacterial blight (Xanthomonas oryzae pv. oryzae) from O. rufipogon. Rice Genet Newsl 15, 138-142.

Zhang, Q., Wang, C., Zhao, K., Zhou, Y., Caslana, V., Zhu, X., Li, DY, Jiang, Q., 2001. The effectiveness of advanced rice lines with new resistance gene $X a 23$ to rice bacterial blight. Rice Genet Newsl 18, 71-72.

Zhou, L., Chen, Z.J., Lang, X.Y., Du, B., Liu, K., Yang, G.C., Hu, G., Li, S.H., He, G.C., You, A.Q., 2013. Development and validation of a PCR-based functional marker system for the brown planthopper resistance gene Bph14 in rice. Breeding Sci 63, 347-352.

Zhou, Y., Qi, H., Wan, B., Lu, X., Zhang, Q., Mou, T., 2003. Studies on Increasing Resistance of 9311 to Bacterial Blight by Molecular Marker Assisted Selection. Mol Plant Breed 1, 343-349.

Zhou, Y.L., Uzokwe, V.N.E., Zhang, C.H., Cheng, L.R., Wang, L., Chen, K., Gao, X.Q., Sun, Y., Chen, J.J., Zhu, L.H., Zhang, Q., Ali, J., Xu, J.L., Li, Z.K., 2011. Improvement of bacterial blight resistance of hybrid rice in China using the Xa23 gene derived from wild rice (Oryza rufipogon). Crop Prot 30, 637-644.

Zhu, R., Huang, W., Hu, J., Liu, W., Zhu, Y., 2013a. Breeding and Utilization of NMS Line Bph68S and Hybrid Rice Liangyou234 Resistance to Brown Planthopper. J Wuhan Univ (Nat. Sci. Ed.) 59, 024-028.

Zhu, R., Huang, W., Hu, J., Liu, W., Zhu, Y., 2013b. Breeding the New Sterile Line Luohong4A of Honglian Type Hybrid Rice. J Wuhan Univ (Nat. Sci. Ed.) 59, 033-036.

Zou, J., Lv, C., Hu, N., Li, Y., Yao, K., 2008. Studies on Ecological Adaptability and Suitable Planting Area of a Two-Line Hybrid Rice Liang-you-pei-jiu. Sci Agr Sin 41, 3563-3572. 